\title{
In-situ database toolbox for short-term dispersion model validation in macro-tidal seas, application for 2D-model
}

\author{
P. Bailly du Bois ${ }^{a, *}$, F. Dumas ${ }^{b}$, L. Solier ${ }^{a}$, C. Voiseux ${ }^{a}$ \\ a IRSN/DEI/SECRE/LRC, Institut de Radioprotection et de Sûreté Nucléaire, Direction de l'Environnement et de \\ I'Intervention, Laboratoire de Radioécologie de Cherbourg, Octeville, rue Max Pol Fouchet, B.P. 10, 50130 \\ Octeville, France. \\ ${ }^{\mathrm{b}}$ IFREMER/DYNECO-Ifremer, centre de Brest, Z.I. de la pointe du Diable, B.P. 70, 29280 Plouzané, France \\ *: Corresponding author : Pascal Bailly du Bois, Tel.: +33 23301 41 05, +332 330141 00; fax: +33 233014130 \\ email address : pascal.bailly-du-bois@irsn.fr
}

\begin{abstract}
:
Appropriate field data are required to check the reliability of hydrodynamic models simulating the dispersion of soluble substances in the marine environment. This study deals with the collection of physical measurements and soluble tracer data intended specifically for this kind of validation.

The intensity of currents as well as the complexity of topography and tides around the Cap de La Hague in the centre of the English Channel make it one of the most difficult areas to represent in terms of hydrodynamics and dispersion. Controlled releases of tritium-in the form of HTO-are carried out in this area by the AREVA-NC plant, providing an excellent soluble tracer. A total of 14,493 measurements were acquired to track dispersion in the hours and days following a release. These data, supplementing previously gathered data and physical measurements (bathymetry, water-surface levels, Eulerian and Lagrangian current studies) allow us to test dispersion models from the hour following release to periods of several years which are not accessible with dye experiments. The dispersion characteristics are described and methods are proposed for comparing models against measurements.
\end{abstract}

An application is proposed for a 2 dimensions high-resolution numerical model. It shows how an extensive dataset can be used to build, calibrate and validate several aspects of the model in a highly dynamic and macrotidal area: tidal cycle timing, tidal amplitude, fixed-point current data, hodographs. This study presents results concerning the model's ability to reproduce residual Lagrangian currents, along with a comparison between simulation and high-frequency measurements of tracer dispersion.

All physical and tracer data are available at (http://doi.pangaea.de/10.1594/PANGAEA.762253). This tool for validation of models in macro-tidal seas is intended to be an open and evolving resource, which could provide a benchmark for dispersion-model validation

\section{Graphical abstract :}

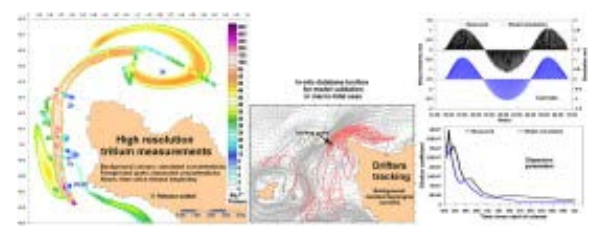

Highlights : $>$ Tritium - in the form of HTO - is used as tracer for validation of dispersion models. In-situ database represents 14,493 tracer measurements and physical recordings. - High frequency model/measurement comparison methods are proposed. Model validation parameters, domain applicability and precision are described. Database provided could be used as a benchmark for dispersion model validation.

Keywords: Modelling ; Data collection ; Tritium ; Dispersion ; Tidal dynamics; English Channel 


\section{Introduction}

\subsection{Objectives}

Realistic simulations of the dispersion of soluble substances in the marine environment are essential for management of the marine ecosystem. Such simulations can be applied to study the fate of chronic or accidental releases into the sea, forming the basis for the construction of ecological models that encompass exchanges between the different compartments of the environment: seawater, living organisms and sediments.

Such tools are particularly useful in seas that are subject to strong anthropogenic pressures, such as the macro-tidal seas of north-western Europe.

Various methods have been tested for calculating the physical behaviour of water masses, as well as advection and dispersion. A number of models can simulate currents and dispersion at very different levels of resolution as well as spatial and temporal coverage. While these models produce an accurate representation of tides and associated currents, even greater accuracy is required to simulate advection of soluble substances over periods longer than the tidal cycle. The small differences observed over a single tidal cycle are amplified after several cycles, especially in areas where currents are strong and bathymetry is complex. The ability of models to reproduce dispersion under realistic conditions of release, wind and tide over several days, weeks or years is a sensitive criterion for evaluating the degree of reliability of the models. The results vary according to the choice of forcing parameters such as bottom and surface friction, as well as the diffusion coefficient.

To test the validity of the methods and parameters used, it is essential to compare simulation results with appropriate field data: this test demonstrates the reliability of a model.

The physical oceanographic data can be acquired with conventional techniques: bathymetric survey, measurement of variations in water levels, current measurements, tracking of drifters.

The data for dispersion of soluble tracers are more difficult to obtain. There are few data that can be used to validate models from the small scale (hours after release, over kilometres) to the scale of coastal seas, and the data that do exist vary in terms of quality and quantity. Nevertheless, the measurement of tracers that are characteristic of identified releases has particular advantages for model validation. Such an approach incorporates all of the phenomena and constraints covered by the models and allows testing over long time scales and extensive areas.

The purpose of this study is to present the choice and collection of field data intended for validation of dispersion models in macro-tidal seas (DISPRO project) with maximum accuracy. The database so formed can be used by modellers to test the reliability of their models against appropriate data. In this way, the study area represents a 'benchmark' for testing the efficiency of models of marine dispersion under realistic conditions.

The validation data and methods proposed are applied to a high resolution $2 \mathrm{D}$ shallow-water model. After a brief description of the model and its nesting strategy, we go on to describe the calibration and validation steps which we consider indispensable for an adequate assessment of the model's capacities. For each measured parameter (sea-surface level, currents, dissolved substances), we give details of the method used for model validation and/or error estimation. In addition, we highlight the available calibration parameters, the sensitivity of the numerical resolution to these parameters and the best achievable performance to be expected in this shallowwater approximation.

This study addresses the following aspects in succession: the choice of area and tracer used to track dispersion; collection of physical data; collection of tracer data; short description of the model applied; data analysis and model / measurement comparison for physical data; characteristics of the measured dispersion; comparison between modelled and measured dispersion; discussion presents sensitive parameters, diffusion coefficients and applicability of tracer data. Conclusion makes a synthesis of the study.

\section{Choice of area and tracer}

Release of dye tracers has been used in many studies over the past forty years to track dispersion over a few hours (Riddle and Lewis 2000). Tracking over several days or weeks requires the use of considerable amounts of dye tracer. Such experiments were performed in earlier studies, sometimes over a period of 15 days (Lapicque 1974). However, to study dispersion over longer periods or carry out repeated measurements for varying conditions of release or forcing, it is necessary to use a tracer already present in the environment.

An ideal tracer should have the following characteristics:

1. It must originate from one or a small number of clearly identified release points;

2. The conditions of release must be precisely known (times, fluxes, etc.);

3. Labelling must be significant, in particular in relation to the pre-existing background level;

4. The tracer must be entirely soluble and not fix onto specific living organisms or sediments;

5. The tracer must not degrade over time;

6. It must be possible to measure the tracer with a high degree of accuracy after dilution in the sea over hours, weeks, months or years after its release; 
7. When the tracer is released in an area difficult to simulate by modelling, it should allow a discrimination of dispersion models in terms of accuracy.

Natural tracers cannot generally be used because of the multiplicity of their source terms and the complexity of the phenomena governing their production and fate in the marine environment.

While the conditions of release can be known for artificial tracers, there are often many release points. Such tracers can also be involved in bio-geochemical processes, and therefore their conservative behaviour in the marine environment cannot be guaranteed.

Radioactive tracers have particularly interesting specific properties, as they generally meet criteria 1 and 2. As regards criteria 4 and 5, some radionuclides exhibit long-term conservative behaviours in seawater: i.e. ${ }^{125} \mathrm{Sb}$, ${ }^{99} \mathrm{Tc},{ }^{3} \mathrm{H}$ (tritium) and to a lesser extent, ${ }^{137} \mathrm{Cs},{ }^{134} \mathrm{Cs}$ and ${ }^{90} \mathrm{Sr}$. Between 1970 and 1995 extensive measurements of all these radionuclides were carried in the seas of north-western Europe (Bailly du Bois et al. 1993, 1995, 1997 and 2002; Bailly du Bois and Guéguéniat 1999; Bailly du Bois and Dumas 2005; Guéguéniat et al. 1994, 1995a, 1995b, 1997a and 1997b; Hermann et al. 1995; Kautsky 1988; Kershaw and McCubbin 1999; Povinec et al. 2003). Reductions in fluxes released during the period from 1980 to 2000 have led to significant decreases in concentrations in the marine environment. Out of the radionuclides mentioned above, only tritium released from nuclear fuel re-processing plants has not undergone a reduction since 1980, while it nevertheless fully satisfies the first six criteria, having a radioactive half-life of $12.4 \mathrm{yr}$ which can be accounted for by the models. The two main sources of tritium are the plants at Sellafield and La Hague, discharging into the Irish Sea and the English Channel, respectively. These plants can be differentiated in terms of the $7^{\text {th }}$ criterion:

The Sellafield outfall is in an area of moderate currents (maximum: $0.5 \mathrm{~m} / \mathrm{s}$ ) and homogeneous bathymetry (10 to $30 \mathrm{~m}$ ), where short-term dispersion appear classical.

The La Hague outfall is close to the Cap de La Hague (Fig. 1), which forms a physical boundary between the Normandy-Brittany Gulf in the west and the middle sector of the Channel towards the east. Because of the coastal geometry, the tide wave coming from the Atlantic is blocked in the west-facing bay formed by the Normandy-Brittany Gulf. This embayment is characterised by considerable tidal ranges (more than $14 \mathrm{~m}$ near the Mont St Michel). The Cap de la Hague represents a bottleneck for the water masses involved during the emptying and filling of this bay two times every day (Online resource 1: tide propagation over the English Channel). This is why the tidal currents close to the cape are amongst the strongest in Europe $(5 \mathrm{~m} / \mathrm{s} \mathrm{during}$ spring tide), with great differences in tidal range near the outfall (varying from $6 \mathrm{~m}$ to $11 \mathrm{~m}$, from the north to the south of the Cap de La Hague, see chapter 3.2). This area is also characterised by varied topography, with pronounced bathymetric gradients (depths from 20 to $100 \mathrm{~m}$ ), the presence of islands, as well as numerous bays and shallows. Based on residual tidal currents, Salomon et al. (1988, 1991 and 1993) have established the long-term dispersion trajectories of dissolved substances. A divergence zone close to the release (see Fig. 2) outfall divides waters flowing into the Normandy-Brittany Gulf from the waters forming part of the general flow from west to east up the Channel and towards the Straits of Dover. As a result, small differences in the conditions of release can lead to opposing directions of dispersion in the medium-term (see chapter 3.3.2 and Bailly du Bois and Dumas, 2002, Fig. 2).

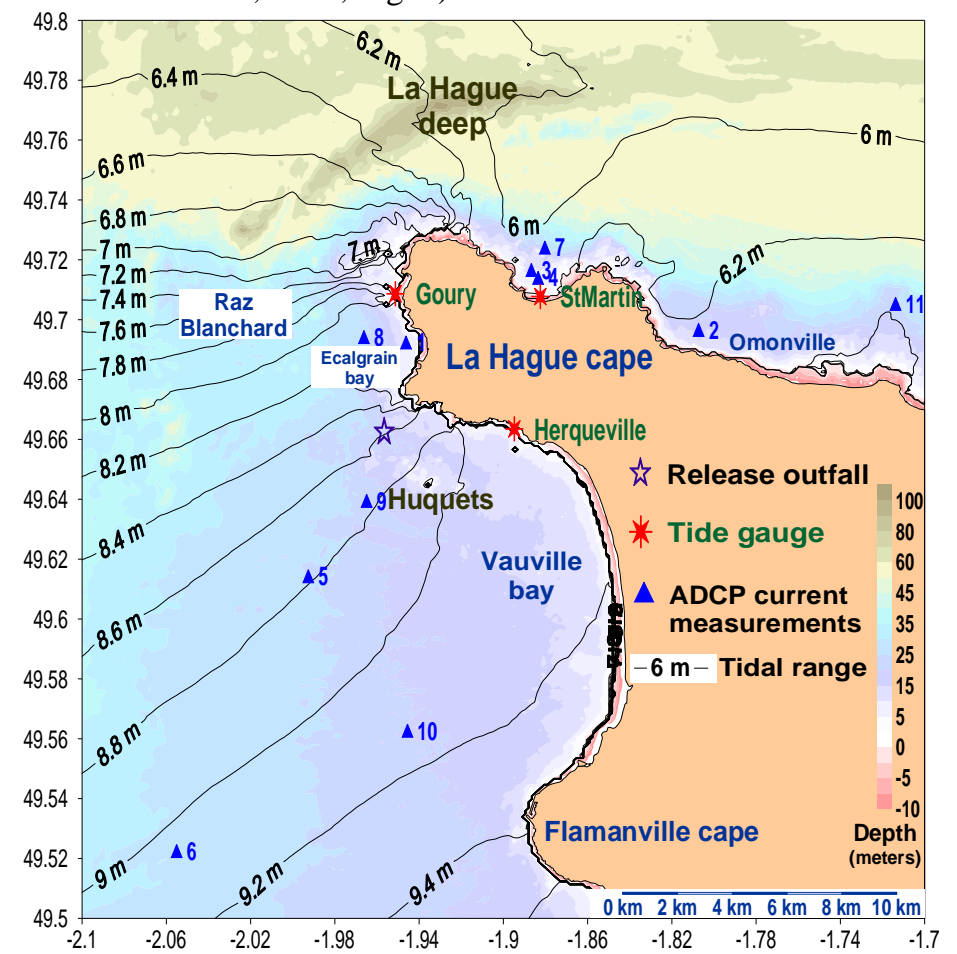

Fig. 1 Location map with simulated tidal amplitude (spring tide), as well as positions of current-measurement and tide-gauge stations near the Cap de La Hague 


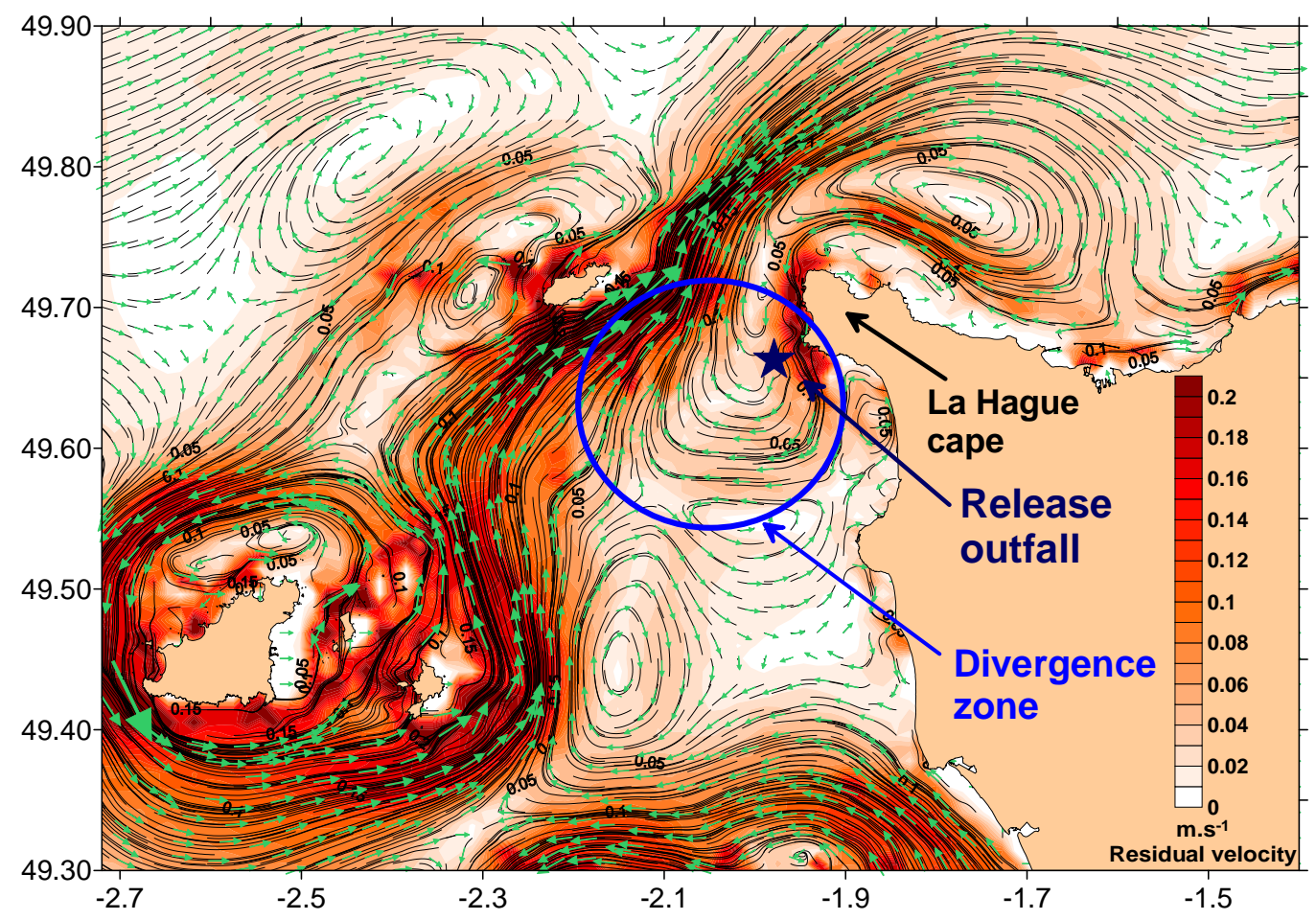

Fig. 2 Mean residual tidal currents in the Cap de La Hague region (according to Salomon et al. 1991)

Because of these morphological and hydrodynamical characteristics, the Cap de La Hague is one of the most difficult areas to model from the point of view of dispersion of soluble substances. A model validated in this area can be considered as robust, and can be applied with confidence to others macro-tidal seas of the European continental shelf.

From an operational point of view, it is also advantageous to have dispersion models fully validated in the English Channel. Such models can be used to simulate the consequences of chronic or accidental releases. The English Channel is particularly sensitive to accidental pollution: a quarter of the world's trade passes through its waters, there are numerous hazards for shipping, and its coasts are subject to strong anthropogenic pressures (fishing, industry and tourism). Frequent accidents occur at sea leading to pollution spills, the most recent examples being the Erika, the Ievoli Sun (2000), the Tricolor (2003) and the Ece (2006).

Much data has been gathered on the dispersion of releases from the La Hague plant into the Channel and North Sea. Data for validation of dispersion models over a month or year are abundant (Bailly du Bois et al., 1995, 1997 and 2002; Bailly du Bois and Guéguéniat 1999; Bailly du Bois and Dumas 2005; Guéguéniat et al. 1994, 1995a, 1995b, 1997a and 1997b; Hermann et al. 1995; Kautsky 1988; Kershaw and McCubbin 1999; Povinec et al. 2003). For shorter time scales and smaller areas, the sampling strategy must be linked closely to the conditions of release from the outfall to obtain data that are relevant for validation. The DISPRO project was initiated because data were inadequate with this purpose in view.

The behaviour of tritium $\left({ }^{3} \mathrm{H}\right)$ released as HTO is strictly conservative as this species represents a constituent part of the seawater and have the same behaviour in seawater as $\mathrm{H}_{2} \mathrm{O}$. Concentrations higher than a few $\mathrm{Bq} / \mathrm{l}$ can be easily measured by liquid scintillation, without the need for radio-chemical preparation. Sampling is easy because the required volumes are small $(8 \mathrm{ml})$. Tritium is a radio-tracer that is highly suitable as regards collection and the carrying out of high-frequency measurements in the environment close to the outfall.

Tritium has been extensively studied as a tracer of water masses labelled by atmospheric nuclear testing. However, given the detection constraints for rapid measurement, this radionuclide has been rarely used for tracking the dispersion of industrial emissions in the marine environment. In this context, Pujol and Sanchez-Cabeza (2000) and Baeza et al (2006) studied the dispersion of tritium released by a nuclear power plant into a river.

The releases from the AREVA-NC nuclear fuel reprocessing plant represent the main source of tritium in the Channel. Releases are of the order of $10^{16} \mathrm{~Bq} / \mathrm{yr}, 100$ times greater than those from a nuclear power plants. In view of the mean flux of water from the Channel to the North Sea, estimated at $126000 \mathrm{~m}^{3} / \mathrm{s}$ (Bailly du Bois and Dumas 2005), these releases would lead to mean concentrations of $2.5 \mathrm{~Bq} / \mathrm{l}$ in the Straits of Dover. Given the concentrations of tritium in seawater entering the Channel (around $0.2 \mathrm{~Bq} / \mathrm{m}^{3}$; Bailly du Bois et al. 2002), the labelling due to the La Hague plant is clear and easily measurable in the eastern Channel. In the coastal areas closest to the outfall, the mean concentration is $11.6 \mathrm{~Bq} / \mathrm{m}^{3}$ (mean for 2002-2005 at Goury; Connan et al. 2006). On average, the La Hague plant carries out one release per day with a tritium concentration of around $10^{8} \mathrm{~Bq} / \mathrm{l}$. The dilution factor of $10^{6}$ measured $1 \mathrm{~km}$ from the outfall (Ausset 1968) would yield concentrations of around $100 \mathrm{~Bq} / \mathrm{l}$, which are easily detectable. 
The results presented here are intended to supplement the data already available for the validation of dispersion models in macro-tidal seas over the short term (1 hour to 1 week) and in a limited area $(1 \mathrm{~km}$ to $30 \mathrm{~km})$. This domain corresponds to the zone of maximum impact of pollutants in the event of an anthropogenic release.

The study area is located in the coastal waters around the Cap de La Hague, in the central sector of the English Channel, within a radius of $30 \mathrm{~km}$ of the release point at the La Hague plant outfall (Fig. 1).

While it is crucial to have the possibility of measuring a conservative tracer for the validation of dispersion models, physical data also remain essential for testing the other outputs of the model.

\section{Physical data}

\subsection{Bathymetry}

Bathymetry is an essential input for hydrodynamic models used to simulate dispersion during the hours following a release. The data provided by the French hydrographic service (SHOM - Service Hydrographique et Océanographique de la Marine, HISTOLYTH data, www.shom.fr) are indispensable.

As some of the SHOM data come from surveys dating back to 1929, additional data were gathered during campaigns by the CNRS - INSU oceanographic research vessel Côtes de la Manche.

Since 2001, all of the bathymetric surveys undertaken by the Côtes de La Manche as part of the DISPRO project and during other missions and transects have been made available to the scientific community by CNRS/INSU (ftp.dt.insu.cnrs.fr /pub/daufin/cdlm). SHOM tools have been used to remove the tides in order to reference depths to the hydrographic datum. The available data cover the entire Channel and part of the Bay of Biscay. In 2008 and 2010, high resolution sonar lateral data have been obtained with Ifremer-Haliotis, a light vessel specially designed for imagery and bathymetry measurements in shallow waters. Specific methods have been used to process different overlapping bathymetric datasets with variable precision (Bailly du Bois 2011). This tool gives a bathymetry file usable for models covering the studied area with an average resolution of $50 \mathrm{~m}$ (Dataset \#762186).

\subsection{Tide-gauge measurements}

A pronounced tidal range gradient is observed in the area around Cap de La Hague, so this particular pattern needs to be reproduced accurately by models in order to simulate the dispersion of soluble substances. When comparing models with measurements, or with a view to operational use, the models must also be able to reproduce the timing and amplitude in water-surface levels which are linked with tidal currents.

Tide gauges were deployed at three stations around the Cap de la Hague to obtain data characteristic of the tide at a high sampling frequency on both sides of the 'boundary' formed by the Cap de la Hague, between areas with contrasting tidal regimes (Fig. 1).

The tide gauges operated at a depth range of $0-10 \mathrm{~m}$, accurate to $3 \mathrm{~cm}$ and with a resolution of $0.3 \mathrm{~cm}$ every $15 \mathrm{~s}$. They were deployed from the coast, at depths close to the lowest low water level. Fig. 1 shows their locations. Difficulties in implementation and data recovery prevented us for establishing an absolute reference datum for vertical positioning of the gauges. The data collected are nevertheless useable to ascertain the tidal cycle timing and amplitude of the tides. A total of 685 tidal cycles were measured; the dates and levels of high and low waters were extracted (Datasets \#762255, \#762256 and \#762257). Table 1 reports the measurement periods and main parameters. The mean tidal range varies by $2 \mathrm{~m}$ between two points at a distance of $5 \mathrm{~km}$ along a straight line to the south and north of the Cap de La Hague; the mean propagation time of the tide between these two points is 28 minutes. The greatest differences are $3 \mathrm{~m}$ for tidal range and more than $2 \mathrm{hrs}$ for propagation of the tide.

\begin{tabular}{|c|c|c|c|c|c|c|c|c|c|c|c|}
\hline & \multicolumn{4}{|c|}{ Measurement period } & \multicolumn{3}{c|}{ Tidal range (m) } & \multicolumn{3}{c|}{ Propagation time (mins) } \\
\hline & Start & End & $\begin{array}{c}\text { Nb. of } \\
\text { tides }\end{array}$ & $\begin{array}{c}\text { Recovery } \\
\text { level }\end{array}$ & Mean & Minimum & Maximum & & Mean & Min. & Max. \\
\hline Herqueville & $07 / 01 / 2005$ & $30 / 01 / 2006$ & 628 & $84 \%$ & 6.19 & 1.79 & 10.16 & $\begin{array}{c}\text { Herqueville } \\
\rightarrow \text { St Martin }\end{array}$ & 28 & -37 & 138 \\
\hline Goury & $07 / 01 / 2005$ & $22 / 09 / 2005$ & 402 & $81 \%$ & 4.93 & 1.24 & 8.20 & $\begin{array}{c}\text { Herqueville } \\
\rightarrow \text { Goury }\end{array}$ & 12 & -25 & 75 \\
\hline St Martin & $07 / 01 / 2005$ & $11 / 05 / 2006$ & 656 & $70 \%$ & 4.06 & 1.24 & 6.60 & $\begin{array}{c}\text { Goury } \\
\text { St Martin }\end{array}$ & 7 & -54 & 105 \\
\hline
\end{tabular}

Table $1 \quad$ Compilation of tide-gauge data

\subsection{Currents}

\subsubsection{Eulerian measurements}

Current measurements were acquired from several stations around the Cap de la Hague over periods of 14-25 hours, using a SONTEK ADP profiler with a frequency of $1000 \mathrm{kHz}$ placed on the seabed (Erreur ! Source du renvoi introuvable., Fig. 1, Datasets \#762262-762381). Current profiles were collected every 15 s, with vertical resolution of $2 \mathrm{~m}$. The currents measured are strongly constrained by the local topography, whereas the spatial resolution and bathymetry data used in the models do not generally allow a faithful reproduction of this topography. 
For this reason, some measurement stations were chosen in areas where the bathymetry appeared more homogeneous and where currents were representative of the overall hydrodynamics of the area (Omonville, Vauville, Flamanville, numbers 2, 5, 6, 9 and 10 in Fig. 1). Nonetheless, all of the measurements were useable for validation of models in either two or three dimensions. The models must have very accurate resolution and appropriate bathymetric data to be able to simulate the currents measured near the coast.

It was not possible to take samples directly in the Blanchard race since the moorings used could not withstand current speeds in excess of $2.5 \mathrm{~m} / \mathrm{s}$.

\subsubsection{Tracking of drifters}

Two Argos drifters were released on 15 March 2007 (Datasets \#762193 and \#762198). These devices are described by Niiler et al. (1995) and validated as being reliable for tracking water-mass movements: they consist of a surface buoy with a GPS receiver and a transmission link towards the ARGOS system. A cable and a $5 \mathrm{~m}$ holey sock are immersed at a depth $15 \mathrm{~m}$. Their drift is representative of the surface currents in this layer. Theses two drifters were released at the same time at a distance of $100 \mathrm{~m}$ apart in the Blanchard race, and then tracked every 30 minutes over 13 days. They were separated by a distance of $54 \mathrm{~km}$ from each other at the time of their retrieval. The trajectories shown in Fig. 3. 3 illustrate the variability of currents in the Cap de la Hague area. The residual trajectories observed comply with those simulated by the lagrangian residual current method with barycentric coordinates (Fig. 2, according to Salomon et al. 1991). The observed drifter trajectories confirm the existence of divergent current trajectories in this area (Fig. 3). Such divergence occurs when topography constrain water masses to strong variations of speed or directions (Islands, straights, gulf and capes ...).

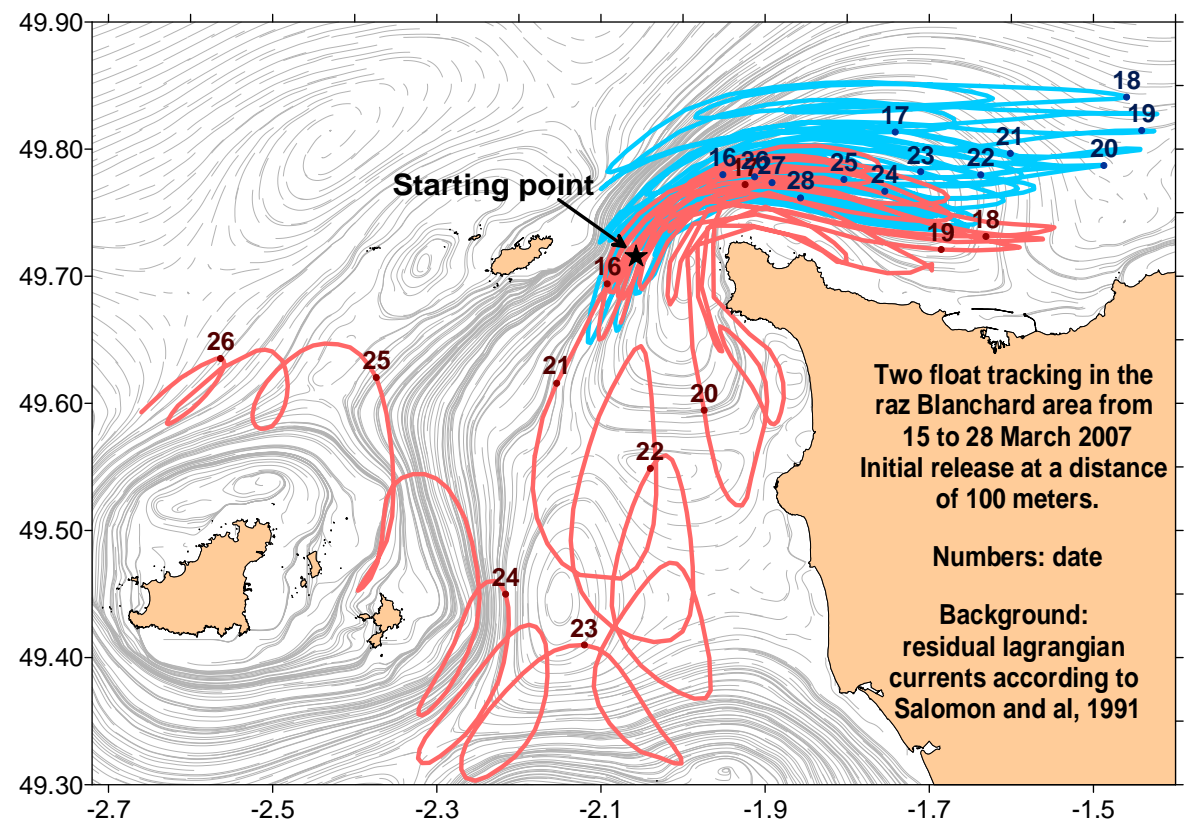

Fig. 3 Trajectories of drifters released at a distance of $100 \mathrm{~m}$ in March 2007 off the Cap de la Hague between 15 and 28 March 2007. Background: Fig. 2.

\section{Collection of tracer data}

\subsection{Sampling strategy}

Before La Hague plant construction, data were acquired using rhodamine as a dye tracer to test the best release location and conditions (Rhodoleïa operations, 1962 and 1963 Ausset and Farges 1968; Lapicque 1974) indicate that the plume can be identified at the surface beyond a distance of $500 \mathrm{~m}$ from the release point; the plume is about $300 \mathrm{~m}$ wide at a distance of $1 \mathrm{~km}$ from the outfall. The associated dilution coefficients are of the order of $10^{-5}$ to $10^{-6}$. Most of the data acquired were qualitative, their accuracy being limited by the techniques used at that time. For releases since 2001, and assuming the dilution coefficients given above, the expected concentrations for tritium released in the form of HTO would be $2000 \mathrm{~Bq} / \mathrm{l}$ and $200 \mathrm{~Bq} / \mathrm{l}$ at $500 \mathrm{~m}$ and $1 \mathrm{~km}$ from the release point, respectively. Releases containing tritium take place almost every day over periods of one to three hours.

The local hydrodynamic conditions (currents of $1-5 \mathrm{~m} / \mathrm{s}$ over a depth of $20 \mathrm{~m}$ ) lead to the vertical homogenization of concentrations after one hour (Ausset and Farges 1968; Lapicque 1974), which explains why, during the DISPRO project, we decided to measure only surface concentrations $1 \mathrm{~km}$ from the outfall along the plume dispersion axis and use a two-dimensional model for simulations. At a later stage, we plan to carry out appropriate sampling to investigate vertical dispersion during the minutes following release at less than $1 \mathrm{~km}$ from the outfall. 


\subsection{Measurement campaigns at sea}

Seven oceanographic campaigns were carried out, each lasting five to ten days, using the CNRS/CIRMAT research vessel Côtes de la Manche, in September and November 2001 (Dispro08, Dispro09 and Dispro10), June and July 2002 (Dispro11 and Dispro12), June 2004 (Dispro04) and April 2005 (Dispro05). Taken together, the campaigns totalled 38 days at sea, during which 14493 samples were collected (Table 2). Fig. 4 shows the distribution of the samples collected in the area around Cap de la Hague.

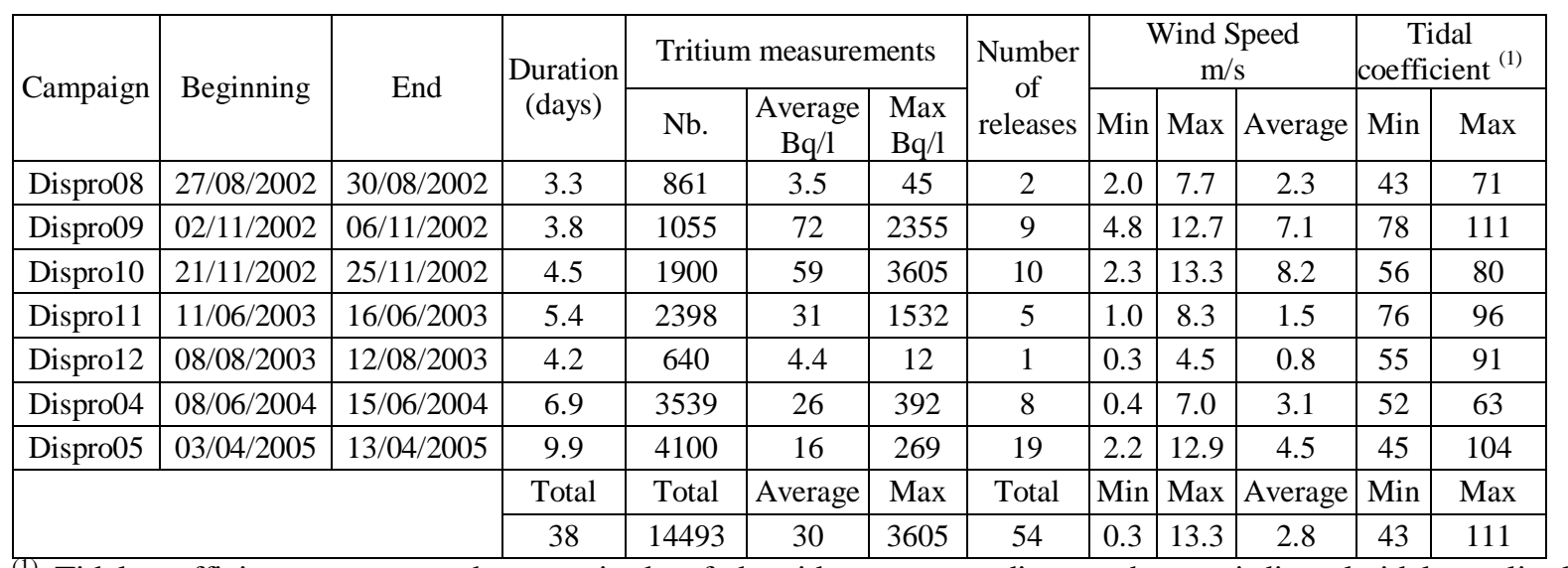

Tidal coefficient represents the magnitude of the tide, corresponding to the semi-diurnal tidal amplitude divided by the mean spring equinox tidal amplitude in Brest. Minimum, average and maximum values are 20, 70, and 120 , respectively.

Table 2 Main characteristics of campaigns undertaken during the Dispro project

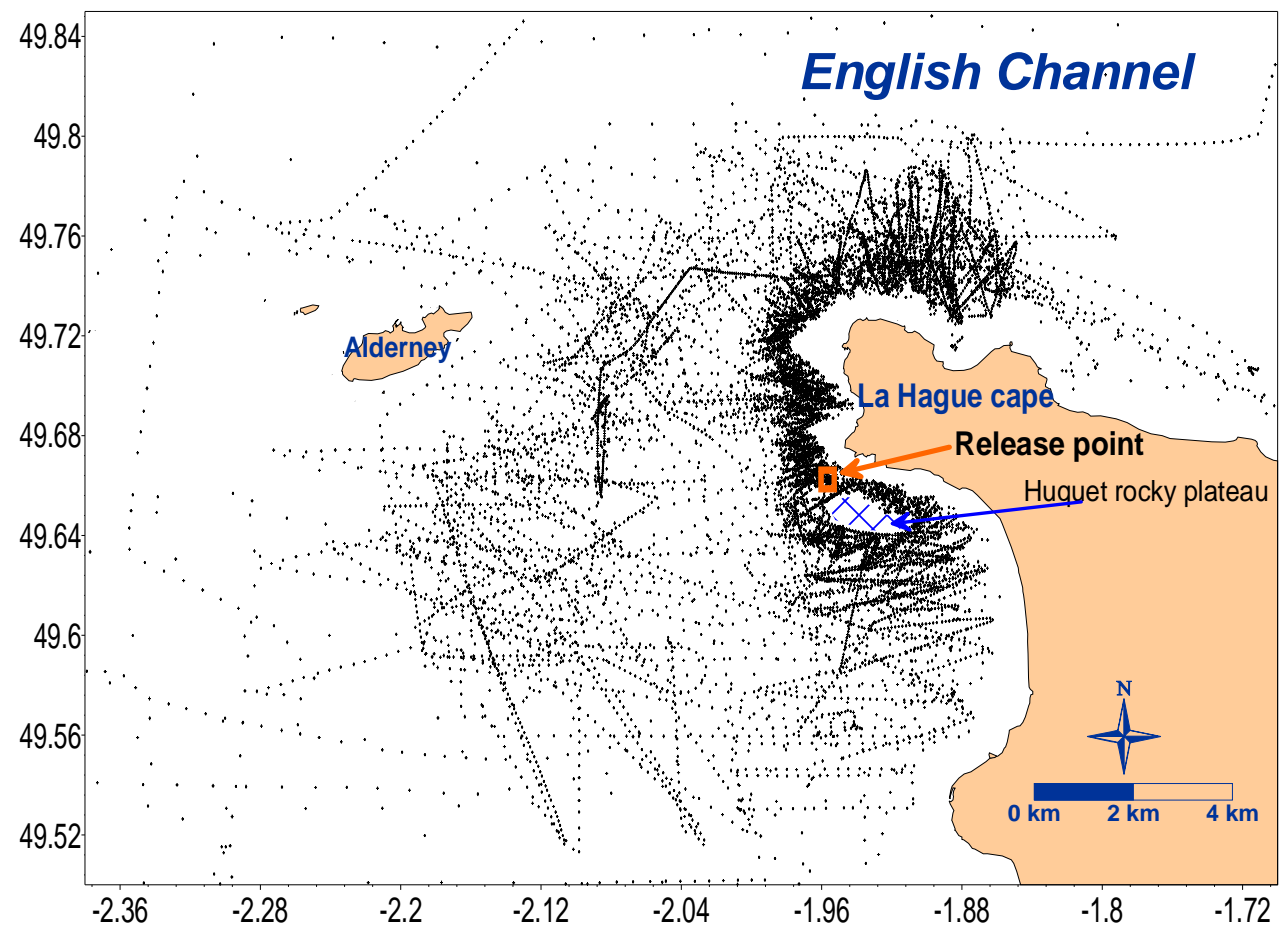

Fig. 4 Sampling points during the DISPRO campaigns in the Cap de la Hague region

\subsection{Positioning in the plume during the campaigns}

Tracer measurements are useful for validation if they provide a better understanding of the position and dilution of the release plume over time. During the hours following release, this implies, in principle, that we have knowledge of the time of release and the area in which the plume will be located close to the outfall. The dynamics of the currents and duration of releases impose precise positioning in time $(15 \mathrm{mins})$ and space $(100 \mathrm{~m})$ to ensure that the sampling zones traversed by the ship's track encompass the plume area (Fig. 6). The planning and timing of releases were transmitted to the vessel by the radiological protection department (Service de Protection Radiologique - SPR) of the AREVA-NC plant. The Mars model (see chapter 5 ; Lazure and Dumas 2008), with a horizontal resolution of $110 \mathrm{~m}$, was used onboard to simulate dispersion prior to release and allow positioning of the vessel during the hours following the start of release. The procedure functioned well, allowing the tracking of 32 individual releases with an average of 300 measurements per release, under varying hydrodynamic and meteorological conditions. 


\subsection{Release data}

The release data provided by the SPR of the AREVA-NC plant were checked and edited for use in the models. The quantity released, as well as time and date of start and end, are indicated for each release (Dataset \#762186). Time of release is calculated by the SPR from the flow rate and volume of the $5 \mathrm{~km}$ outfall pipe. Uncertainty with regard to release times is estimated at 15 minutes.

\subsection{Tritium measurements}

For tracer measurements, we collect water samples at a high frequency knowing exactly the time and place of sampling. Samples were collected under way every $30 \mathrm{~s}$ over two to five hours following each release, i.e. 250 to 600 samples per release. This sampling frequency was increased for tracking over greater distances.

One objective was to minimize the transit time of the water from the sea to the vial. As tracer concentrations become vertically homogenized one hour after release, samples were taken near the surface $(3 \mathrm{~m})$ with the onboard fire fighting pump running continuously at a high flow rate. The sea water was pressurized $(2-4 \mathrm{hPa})$ by a by-line connected to a MICROPUMP® pump, and was then filtered at $0.2 \mu \mathrm{m}$ through a Sartorius Minisart ${ }^{\circledR}$ filter cartridge. Each sample comprises 30 to $50 \mathrm{ml}$ of sea water collected in 5 to $15 \mathrm{~s}$. Given the speed of the vessel, these samples represent the concentration in sea water integrated over a horizontal distance of 25 to $75 \mathrm{~m}$. The location and number of each sample was recorded automatically. The overall transit time of the sea water between the surface and sampling bottle is evaluated at $15 \mathrm{~s}$, based on transects carried out close to the outfall where the plume is still in alignment. During the five days following collection, the samples were prepared for measurement by mixing $12 \mathrm{ml}$ of Ultimagold LLT cocktail with $8 \mathrm{ml}$ of filtered seawater in $20-\mathrm{ml}$ low diffusion Packard® vials. The vials were stored at $5^{\circ} \mathrm{C}$ away from the light until measurement with a Packard Tri-Carb 2700TR Liquid Scintillation Analyser. The standard solutions and calculation of concentrations by volume from raw data were handled entirely by the LRC.

An inter-comparison study was carried out in 2003 involving the measurement of tritium in seawater, using a standard reference value of $20.1 \pm 1.3 \mathrm{~Bq} / \mathrm{l}$; the value obtained by the $\mathrm{LRC}$ was $18.0 \pm 1.5 \mathrm{~Bq} / \mathrm{l}$; the mean value for the participating laboratories was $18.8 \pm 1.7 \mathrm{~Bq} / \mathrm{l}$ (IRSN 2003).

\subsection{Tritium model/measurements comparison method}

Since hydrodynamic models have a limited coverage, it is therefore difficult to use them to simulate tracer concentrations resulting from releases made several months or years ago. This also applies to background levels corresponding to natural and anthropogenic inputs (fallout from atmospheric nuclear testing over the entire northern hemisphere). When these concentrations are not accessible via modelling, they need to be estimated from measurements carried out in the region and on a wider scale.

For tritium concentrations in waters entering the Channel, we obtained values from campaigns in the Atlantic and Channel (GEDYMAC, ATMARA, ARCANE, CIROLANA, OVIDE and ASPEX campaigns). For the period 2001-2009, the background level is estimated currently at $0.1-0.2 \mathrm{~Bq} / \mathrm{m}^{3}$.

As regards tritium derived from previous releases, we can calculate concentrations using models with a wide footprint and over extended periods so as to define initial conditions for detailed models. Background levels can also be estimated from the measurements presented here. However, it must be emphasised that the Cap de la Hague area is at the boundary between waters coming from the western Channel, which are only weakly labelled, and waters from the Normandy-Brittany Gulf, which are affected by releases from the AREVA-NC plant over several months (Fraizier et al. 1992, Boust et al. 1995; Salomon et al. 1991; Bailly du Bois and Guéguéniat 1999). The background concentration resulting from previous labelling is therefore not homogeneous.

The discrepancies between simulated and measured concentrations are calculated conventionally by comparing the simulated values with measurements taken at the same dates and places. Statistical comparisons can be applied to these two series of values. Examples of this kind of comparison are presented in Bailly du Bois and Dumas, 2005.

In the vicinity of an outfall, the representativity of dispersion simulations can be assessed in finer detail, release by release. Such a method is presented below.

The sampling strategy adopted is to transect the release plume as many times as possible during dispersion of the release. Each transect is given an identification number.

Usable transects are selected when measurements indicate that the release plume has actually been intersected, and that the release can be identified with confidence by simulating the dispersion of the release in question. The following parameters are calculated for each transect:

- The characteristics of the release intersected (start, finish, tritium concentration)

- Time since start of release

- Distance from release outfall

- Position in relation to outfall (north, south)

- Maximum concentration in the plume

- Mean concentration in the plume

- Width of plume intersected 
The ability of a model to reproduce the in situ measurements can then be tested for each of the above criteria. In the example given here, we were able to use a total of 329 transects made between 10 minutes and 48 hours after the start of an identified release, which includes 2572 individual measurements. The remaining 11921 results can be processed with traditional methods for comparing models with measurements.

To allow comparison between dilution results from different releases, the measured concentrations in $\mathrm{Bq} / \mathrm{m}^{3}$ are converted into dilution coefficients calculated from the released concentration giving rise to the labelling. The dilution coefficient, DC, is expressed as follows:

$$
D C=\frac{B q \cdot l^{-1}{ }_{M}}{B q \cdot l^{-1}} .
$$

Bq. ${ }^{-1}{ }_{\mathrm{M}}$ : measured concentrations

Bq..$_{\mathrm{R}}^{-1}$ : released concentrations

For a given transect, the plume width is obtained by locating the points on the transect lying on either side of the maximum of the mean concentration, which is calculated from the maximum and minimum concentrations measured along the transect. The plume width is measured at half height $\mathrm{W}$ (width at half maximum). Considering a normal (Gaussian) distribution, this value corresponds to the maximum variation of concentration along the transect, and is the more precise to calculate and compare with a limited number of samples. Fig. 5 shows an example of the method of calculation for a transect, with the corresponding calculation using the concentrations simulated for the same dates and locations as the measurements.

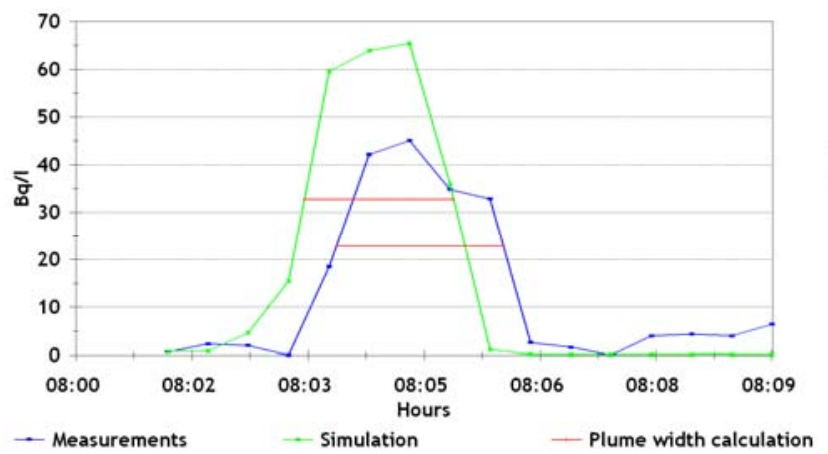

a)

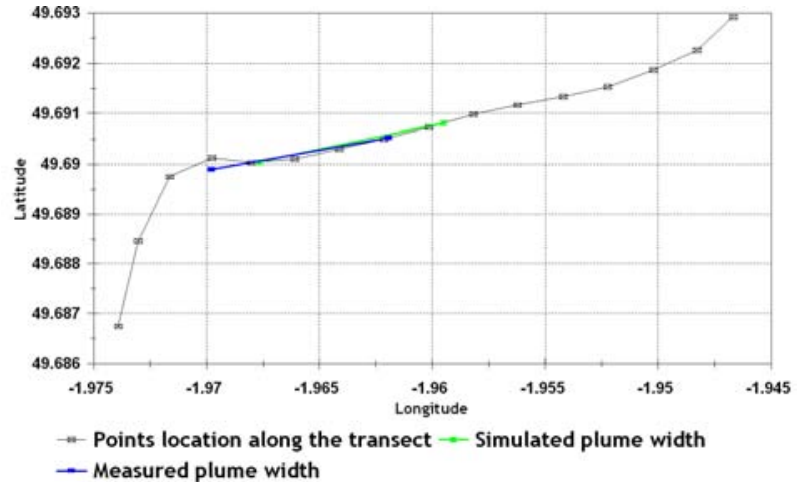

b)

Fig. 5 Calculation of measured and simulated plume width: a: variations of concentration with time; $b$ : corresponding spatial position of zones used for calculating plume width

Given the intensity and complexity of currents, the data collected in the hours following a release cannot be used to produce a synoptic chart summarizing dispersion. Displacement of the plume has to be tracked step by step with short time steps. Fig. 6 presents a comparison of model vs. measurements for the 4 hours following a release. The model applied for this comparison is described in Chapter 5. Online resource 2: Plume dispersion around the La Hague Cape shows an animation of the plume dispersion during this survey and days following in real weather and release conditions. It reveals the complexity and variability of the plume dispersion in this area. On the day in question, 348 tritium measurements were acquired between 16:15 h and 19:50 h; 29 transects were carried out, corresponding to an average of 12 measurements per transect. Dispersion had to be determined every 15 minutes to obtain an accurate tracking of the plume movement. The release began at 16:10 h, and was detected at the surface 10 minutes later (Fig. 6 a). Fifty minutes elapsed (Fig. $6 \mathrm{f}$ at $17.00 \mathrm{~h}$ ) before the concentrations measured at the surface converged with the simulated values. This example shows the importance of precise positioning of the vessel in the release plume. Moreover, the model must be able to forecast dispersion of the release plumes to ensure sampling at the right place and time. An error of 15 minutes or $500 \mathrm{~m}$ is sufficient to render the collected data unusable. With a 15 minutes delay, a significant part of the releases could be missed with an average release duration of two hours. This is of more importance when release is made at the time of the tide return between flood and ebb. Concerning sampling location, the plume had only a 100-2000 m width during the first six hours following the release and thus transects are as close as possible of the plume in order to minimise the number of samples. 


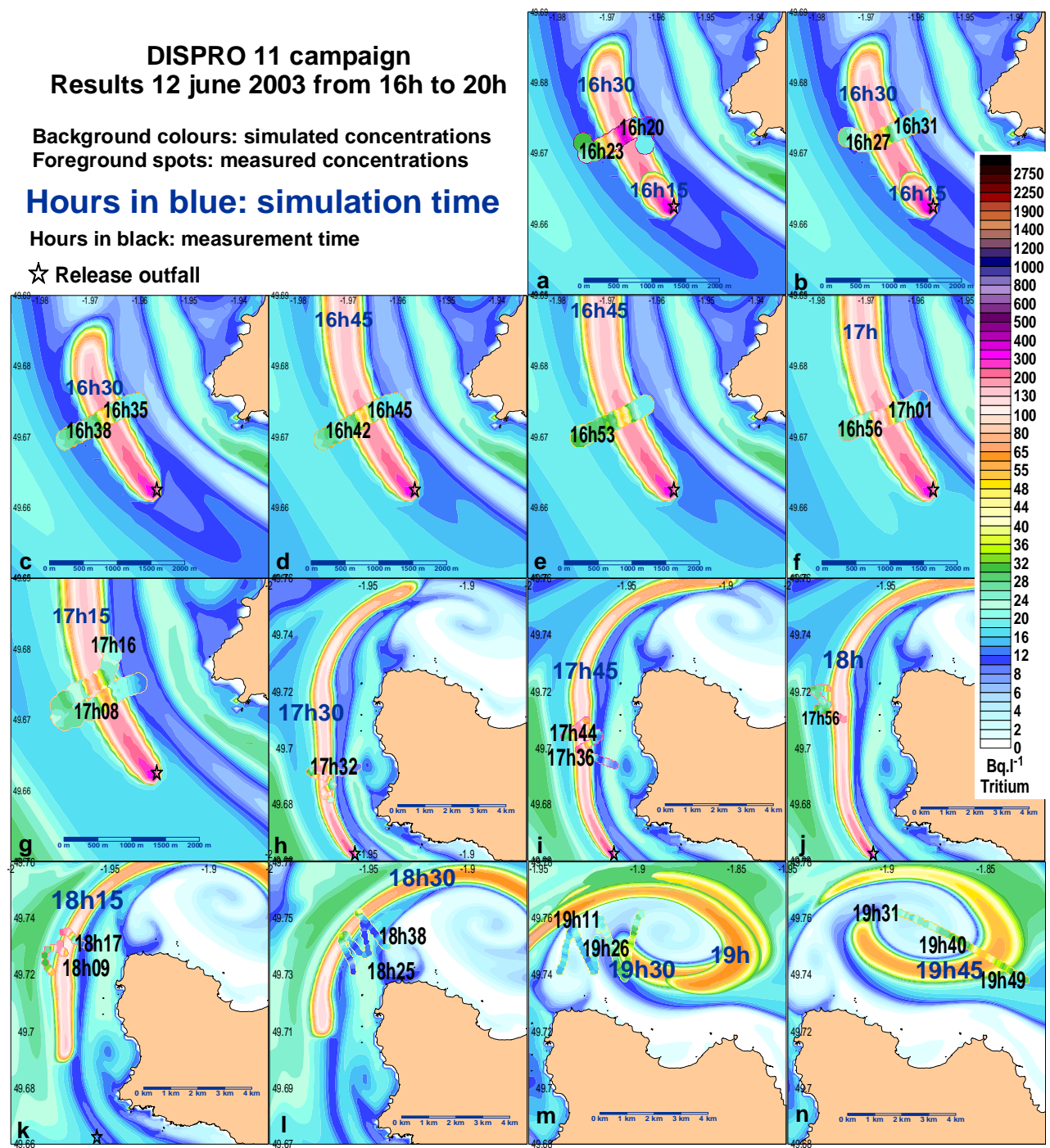

Fig. 6 Example of comparison between measured and simulated dispersion during 4 hours after release

Beyond 24 hours after the time of release, it becomes increasingly difficult to attribute a measured plume to a given release because of the inter-mixing of successive releases. The model vs. measurement comparison is then limited to concentrations that are simulated and measured individually (11921 measurements).

All tritium measurements, transect and release identification are available in dataset \#762261.

\section{Model applied}

The study area is focused on the outlet point of the La Hague plant, located mid-way along the French coast of the Channel. Numerous modelling studies (e.g. Bailly du Bois and Dumas, 2005; Salomon et al, 1991) have demonstrated that models using two-dimensional horizontal approximation (i.e. shallow-water equations) are capable of producing a satisfactory representation of dissolved-substance transport.

These equations were solved using the finite-difference Mars model, with implicit alternate direction timestepping for gravity-driven inertia waves. Non-linear terms were discretized semi-implicitly. Full details concerning the Mars algorithm are given by Lazure and Dumas (2008).

The present model involves a nesting strategy, starting from a broad region covering the entire North-West European continental shelf (with a 5-km grid resolution) down to a detailed domain covering a few tens of $\mathrm{km}$ (with a 110-m resolution). The resolution of the targeted area required to manage the drying and flooding of the tidal flats so that this capability of Mars was switched on.

The full nesting pattern is shown in Fig. 7. 


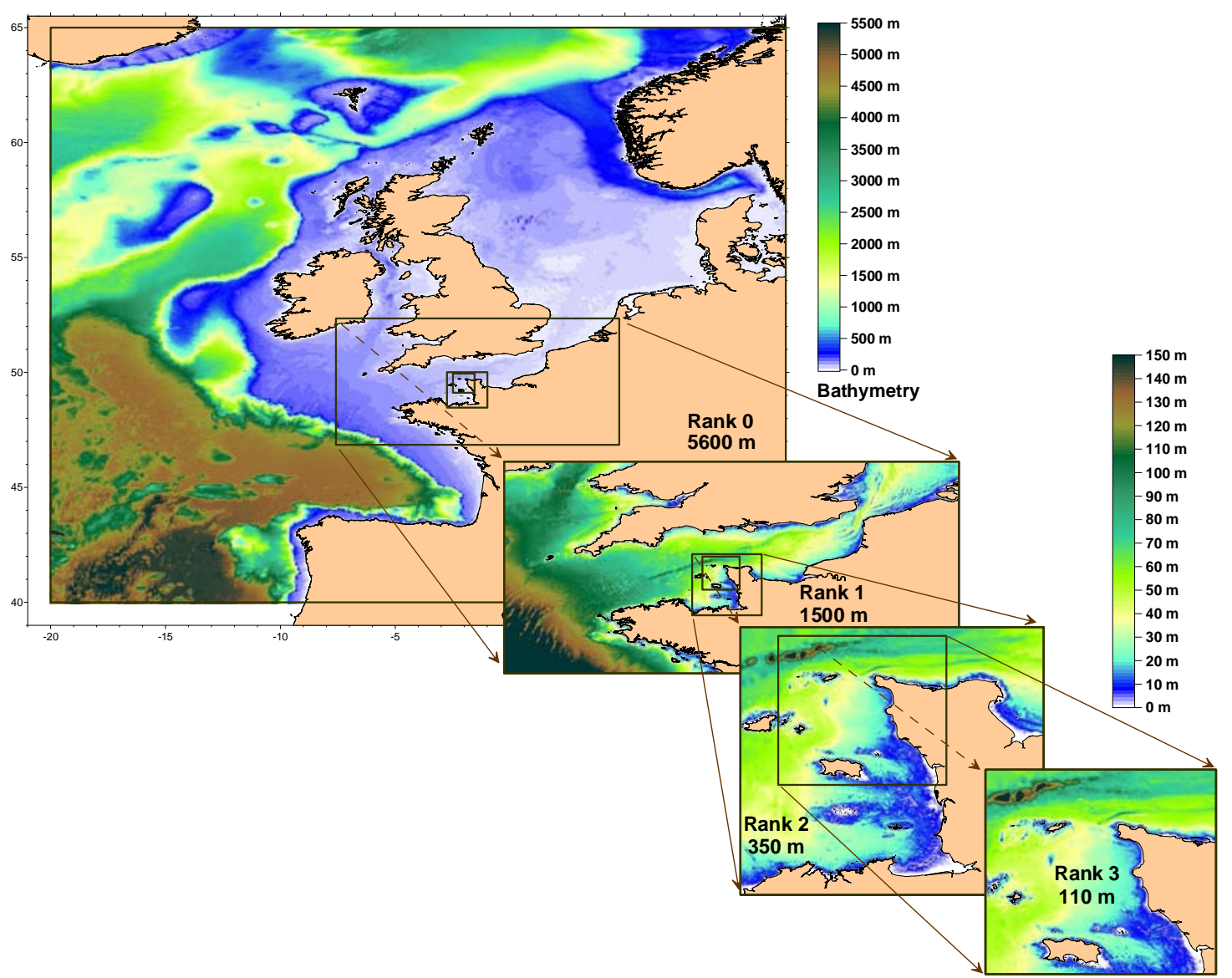

Fig. 7 Model nesting

In the largest domain the baroclinic effects can be neglected (so that 2D models can relevantly be used) as long as they do not influenced that much the targeted area of "the cap de la Hague". Of course they play a major role over the shelf of the bay of Biscay (where large internal tide have been evidenced for years) or next to the mouth of large estuaries (Loire, Gironde, Rhine...) but around the cap de la Hague the ocean is neither thermally stratified nor stratified in terms of salinity and temperature ; it is due to the strong tidally induced mixing and the lack of significant river outflow. Baroclinic processes is thought to play a significant role in the propagation of the barotropic tide (thanks to energy dissipation within the internal tide processes) but it is empirically corrected within the scope of this study by adjusting the bottom friction at large scale.

The bathymetry at the grid nodes of the different models is estimated from various data sources described in chapter 3.1 .

Data exchange between models is unidirectional (one-way nesting), from the broadest coverage model to the finest-scale high-resolution model. The first three levels of the nested model only calculate barotropic dynamics, yielding the open boundary conditions (i.e. sea surface elevation and the mean current) to the next lower rank.

The free-surface levels imposed along the open boundaries of the mother grid are prescribed using the harmonic components provided by the FES2004 global tide model (Lyard et al., 2006). The spectrum of this numerical solution is made of ten components (O1, K1, P1, Q1, M2, S2, N2, K2, 2N2 and M4). In addition to this astronomical-tide solution, we apply an inverse barometric correction to account for incoming surge.

Both the atmospheric pressures and wind fields are picked up in analyses carried out by the forecast and analysis systems of French and European meteorological services (i.e. ECMWF and Aladin from Météo France). The ECMWF analyses have a six-hour time resolution and a $1^{\circ}$ spatial resolution whereas Aladin analyses have a three-hour time resolution and a $0.1^{\circ}$ spatial resolution. Wind at $10 \mathrm{~m}$ and pressure fields are interpolated linearly on the various grids of the models. Surface stress is calculated conventionally, using the 10-m wind data.

Radiotracer dispersion is only calculated for the finest-scale rank in cases where the coverage is set in such a way that the release plume does not reach the open boundaries during the first 48 hours of monitoring of the release studied here. Beyond that time limit, measurements show that dilution and mixing prevent the differentiation of one release from another. 


\section{Data analysis and hydrodynamic model/measurement comparison for physical data}

\subsection{Sea-surface level}

\begin{tabular}{|c|c|c|c|}
\hline Station & St Martin & Goury & Herqueville \\
\hline \multicolumn{2}{|c|}{ Tidal ranges (meters) } \\
\hline Mean observed tidal range & 4.06 & 4.93 & 6.19 \\
\hline Mean modelled tidal range & 4.09 & 4.98 & 5.82 \\
\hline Variation & $1 \%$ & $1 \%$ & $6 \%$ \\
\hline Max. observed tidal amplitude & 6.60 & 8.20 & 10.16 \\
\hline Max. modelled tidal amplitude & 6.32 & 7.64 & 8.96 \\
\hline Variation & $4 \%$ & $7 \%$ & $12 \%$ \\
\hline Min. observed tidal amplitude & 1.24 & 1.24 & 1.79 \\
\hline Min. modelled tidal amplitude & 0.90 & 1.05 & 1.23 \\
\hline Variation & $27 \%$ & $15 \%$ & $32 \%$ \\
\hline Temporal variations of the tidal cycle (minutes) \\
\hline Mean deviation & -2.0 & 2 & -3 \\
\hline Standard deviation of variations & 20 & 14 & 16 \\
\hline
\end{tabular}

Table $3 \quad$ Comparison of recorded and modelled Sea-surface levels

Mean tidal ranges vary by about $1 \mathrm{~m}$ from one station to another, with stations being less than $5 \mathrm{~km}$ apart. These recordings confirm the rapid spatial variation of tidal parameters in this area. The model rank 2 (Fig. 7) was used for model/measurement comparison. The discrepancies in mean tidal range are of the order of $1 \%$ for Goury and Saint Martin, and around 5\% $(30 \mathrm{~cm})$ for Herqueville where tidal amplitudes are greater. The model tends to underestimate tidal amplitudes for Herqueville and slightly overestimate them for Goury and Saint Martin.

If we consider spring-tide related events (see Table 3), results are accurate to within 4-12\%, whereas the simulation of neap-tide related events produces the worst discrepancies, which reach $32 \%$ for Herqueville. The large discrepancies in tidal-range during neap-tides are not surprising in a coastal area where tidal spectra are much richer than offshore, due to major non-linearities (friction, advection and, above all, divergence of water-mass). A significant part of the tidal energy is therefore stored in quarter-diurnal, sixth-diurnal tidal components. These tidal components are usually generated with less precision by models because the terms producing these non-linear waves strongly depend on uncertain parameters (bathymetry and bottom friction). During neap tides, the dominant M2 and S2 waves display a $180^{\circ}$ phase shift, implying that, at these particular stages of the tidal cycle, high-frequency waves have proportionally more influence. This increases the occurrence of errors related to the lack of precision of the generating terms.

Taken together, standard deviations for tidal amplitudes range from 30 to $40 \mathrm{~cm}$, which represents an overall error of the order of $10 \%$.

Bottom of Table 3 shows mean variations of tidal cycle phasing order of only a few minutes, which means that there is no significant bias. Regarding the standard deviation, we note that the typical deviation for a given tide is of the order of 15-20 minutes. This degree of precision is similar to that of the release times and, most probably, more precise than the data available during a crisis event for a pollutant release (ship grounding, accidental industrial releases, etc.). Such precision is remarkable considering the simulated propagation of the tidal wave over more than $1000 \mathrm{~km}$ (Fig. 7).

These aspects of the tidal cycle are explored below, using current measurements to pinpoint more accurately the reverse times of the tide.

\subsection{Fixed-point Current measurements, calibration of sea-floor drag coefficient}

The measured currents are averaged in the vertical dimension to be compared with the currents simulated by the 2D model. Fig. 8 presents the mean measured and simulated current vectors. Only one measured and one simulated value out of eight is shown. This type of representation allows a simultaneous comparison between the simulated and measured results for amplitude, current direction and tidal cycle timing. 


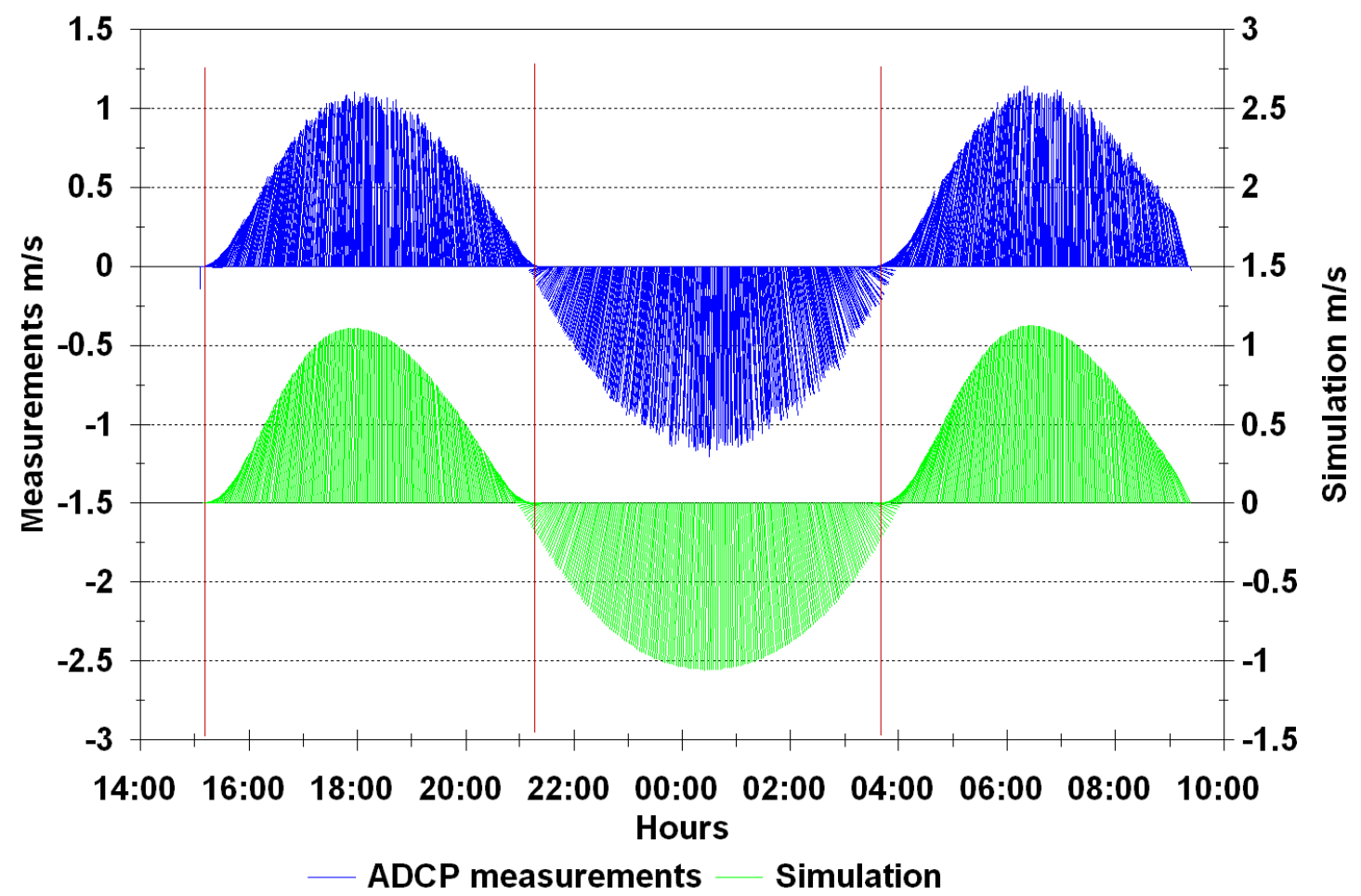

Fig. 8 Fishbone diagram of measured and simulated current vectors at Flamanville, august 10 2003, average every two minutes

The main discrepancy concerns the durations of ebb and flow, which are not identical: the observed flow duration is about fifteen minutes longer than the simulated one (vertical reference marks on Fig. 8). This implies that, if the changeover from flow to ebb is correctly synchronized, the changeover from ebb to flow shows a 15minute shift in time. This feature constrains the precision that can be expected from the model, based on our comparison between modelled and measured data; in fact, the temporal precision can never be less than 15 minutes. Note that this time discrepancy is of a similar order of magnitude as the discrepancies in time phasing of water surface levels.

Two stations were selected for comparing the modelled and measured data: Vauville and Flamanville. They were positioned in areas with the most homogenous bathymetry and where the currents are representative of the average flow transiting around the Cap de La Hague. The mean discrepancies between measured and simulated currents at have been quantified, and the results are summarized in Table 4.

\begin{tabular}{|c|c|c|c|c|}
\hline \multirow{2}{*}{} & \multicolumn{2}{|c|}{ Vauville } & \multicolumn{2}{c|}{ Flamanville } \\
\cline { 2 - 5 } & $\begin{array}{c}\text { Current velocity } \\
\text { modulus }\end{array}$ & Direction & $\begin{array}{c}\text { Current velocity } \\
\text { modulus }\end{array}$ & Direction \\
\hline Mean & $4 \%$ & $4.7^{\circ}$ & $1 \%$ & $2.6^{\circ}$ \\
\hline Standard deviation & $20 \%$ & $12^{\circ}$ & $10 \%$ & $6.4^{\circ}$ \\
\hline
\end{tabular}

Table $4 \quad$ Mean discrepancy between measured and simulated flow velocities at Vauville and Flamanville

These discrepancies refer to measured or simulated instantaneous velocities and directions at a given geographical point (Eulerian monitoring). They reveal a good agreement between simulated and measured currents. The simulation of currents is noticeably better at Flamanville (which is deeper and further away from the coast, and therefore in an area of more homogenous bathymetry) than at Vauville (Fig. 1). The agreement between flow directions is due to the marked bimodal periodicity of the currents with their preferential North-South orientation.

A more detailed comparison can also be made by plotting the progressive vector diagrams of the currents during the measurement period, which is used for calibration of bottom drag coefficient (Fig. 9). We use a ManningStrickler type parameterization into which the bottom drag coefficient can be expressed as:

$$
C_{d}=\frac{g}{S t^{2} H^{1 / 3}}
$$

Which expresses the bottom drag as a function of water-column depth. Strickler's coefficient (St) depends notably on the nature of the sea bed, particularly its roughness.

Two methods allow us to improve the calibration of our model as regards the measurement points: we can analyse the impact of a change of Strickler's coefficient on the progressive vector diagrams and on the cumulated square current moduli, expressed by the following terms: 


$$
\begin{aligned}
& \vec{u}\left(x_{0}, t\right)=\int_{t_{i}}^{t} \vec{u}\left(x_{0}, t^{\prime}\right) d t^{\prime} \\
& \left\|\vec{u}\left(x_{0}, t\right)\right\|^{2}=\int_{t_{i}}^{t}\left\|\vec{u}\left(x_{0}, t^{\prime}\right)\right\|^{2} d t^{\prime}
\end{aligned}
$$

The progressive vector diagram can be interpreted in terms of the distance travelled, whereas the cumulated values of the integrated squared modulus can be directly related to the kinetic energy. This implies that, by setting a more realistic value for the cumulated kinetic energy, we can more satisfactorily take into account dissipation due to sea-floor drag (the predominant factor in energy dissipation).

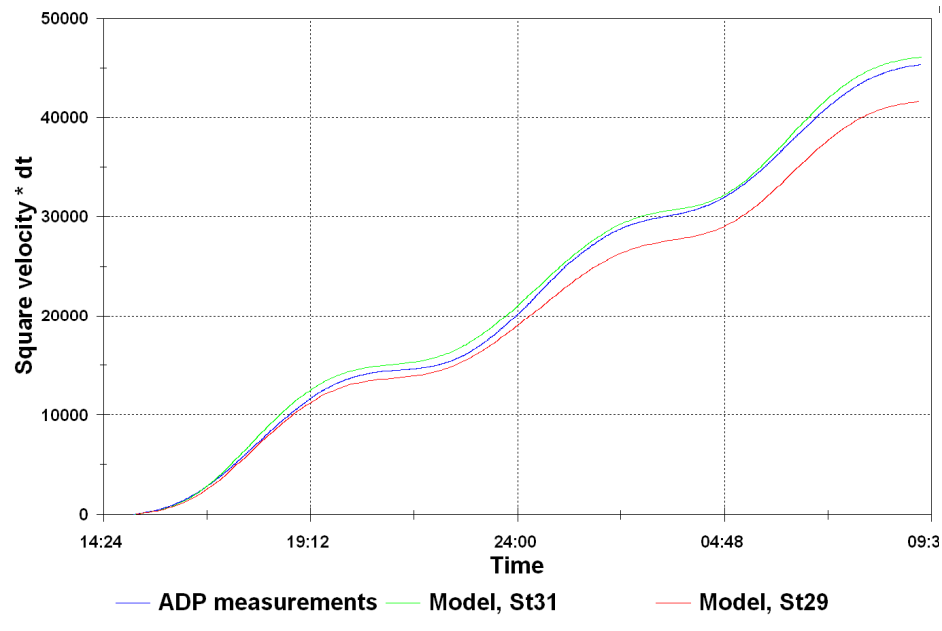

a)

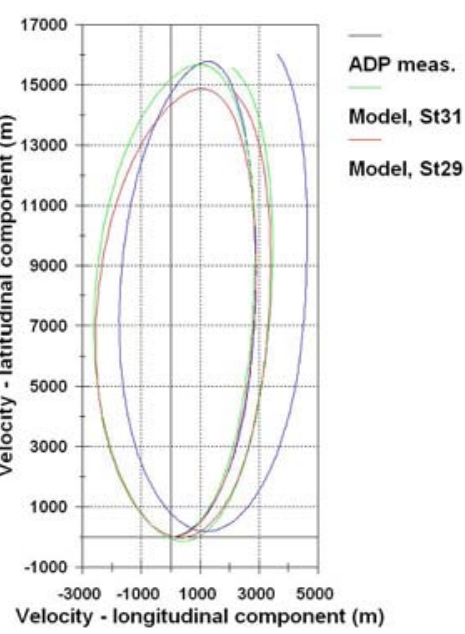

b)

Fig. 9 a) Time Integrated square current moduli at Flamanville on 10th and 11 th August 2003, mean tide (in $\left.m^{2} \cdot s^{-1}\right)$ b) Progressive vector diagram for the same point (horizontal and vertical scale in $m$ )

Fig. $9 \mathrm{a}$ and $\mathrm{b}$ illustrate, for the Flamanville point, the sensitivity of these parameters to variations of Strickler's coefficient, along with the results of the comparison to the parameters calculated from observations. A significant impact is observed, even with very minor variations of Strickler's coefficient ( 2 units). This demonstrates how the value of 29 for Strickler's coefficient can be further refined after calibration of the water-depths and currents when taken as a time series. We finally adopt a Strickler's coefficient of 31 as being the most representative of current energy. This gives a drag coefficient ranging from $10^{-3}$ to $5.10^{-3}$, in accordance of typical value (Dronkers, 1964; Pingree and Griffiths, 1987).

Although the progressive vector diagrams are very similar, a significant discrepancy in distance is cumulated over one tide (from 4 to $29 \%$ in terms of distance).

To sum up the various aspects of this fixed-point comparison, we note that:

- Instantaneous velocities are well simulated by the model, with an average discrepancy of less than $20 \%$;

- Discrepancies of 5 to $30 \%$ are to be expected with long-term transport simulations (Lagrangian application of a Lagrangian approach);

- The best time-calibration of the model still involves a \pm 15 -minute time lag.

Such discrepancies in Eulerian currents would strictly correspond to those obtained from a Lagrangian approach if the hydrodynamic fields were homogenous in space. Indeed, Longuet Higgins (1969) gives a $1^{\text {st }}$-order expression of Lagrangian velocity:

$$
\overrightarrow{\vec{u}(x, t)}=\overrightarrow{\vec{u}\left(x_{0}, t\right)}+\overline{\int \vec{u}\left(x_{0}, t\right) d t \bullet \overrightarrow{\nabla u}\left(x_{0}, t\right)}
$$

with

$$
x=x_{0}+\int_{t_{0}}^{t} \vec{u}\left(x^{\prime}, t^{\prime}\right) d t^{\prime}
$$

Where $x^{\prime}$ is the position at time t'. The second term represents Stokes' drift velocity and reflects the spatial variations of the hydrodynamic field. If the latter fall to zero, Eulerian and Lagrangian velocities are found to coincide. The major bathymetric irregularities of the area cause large spatial gradients of the hydrodynamic features and consequently a large Stocke's drift. To point out errors arising along the plume trajectory, the problem should be analysed from a strictly Lagrangian point of view. 


\subsection{Lagrangian drifter tracking}

The trajectories of drifters can be simulated by models and compared with the observed trajectories. This type of comparison is hindered because the pronounced current gradients in the Cap de la Hague area give rise to diverging trajectories. As soon as the observed and simulated trajectories begin to diverge slightly, the comparison becomes irrelevant. This phenomenon is clearly shown by the tracking of two drifters released at the same point at the same time (Fig. 3).

Trajectory monitoring allows us to confirm the lagrangian velocities simulated by the model. Measurements carried out near the sea surface are compared with the vertically integrated current data: the drifters travel at a maximum depth of $10 \mathrm{~m}$, whereas, along the trajectories, water depths range from 20 to $50 \mathrm{~m}$ or more.

Major discrepancies are clearly revealed by simply comparing simulated and observed trajectories over the entire observation period. This is because the observation method induces a build up of errors: trajectories rapidly diverge due to the considerable variability of local currents. Nevertheless, we can see from Fig. 3 that the trajectory of the drifters compared with the flow lines modelled using the same type of model as Salomon et al. (1991) is highly consistent with the incursions of the drifters: numerous to and from movements in the North are followed by a southerly route along the eastern edge of the recirculation cell, offshore from Flamanville, and finally Southward exportation of the flow towards Alderney. This suggests that the model should behave satisfactorily when reproducing medium-term transport.

In addition, Lagrangian drifter measurements are analogous to mobile current meter data: the current velocity measured by the drifters all along their trajectory is compared to values acquired using the same time-discretization which is available and sampled in the model. Fig. 10 shows a geographical compilation of absolute values of the discrepancies. Relative discrepancies (coloured background) represent the differences between the intensities of the drifter measured current and the simulated current $\left(\left(\mathrm{U}_{\text {meas }}-\mathrm{U}_{\mathrm{sim}}\right) / \mathrm{U}_{\text {sim }}\right)$. Ponctual differences are interpolated to draw the background coloured map. Vectors represent the residual current after difference between the drifter-measured and simulated currents. The largest discrepancies are observed in spots North-West and South of the Cap de La Hague.

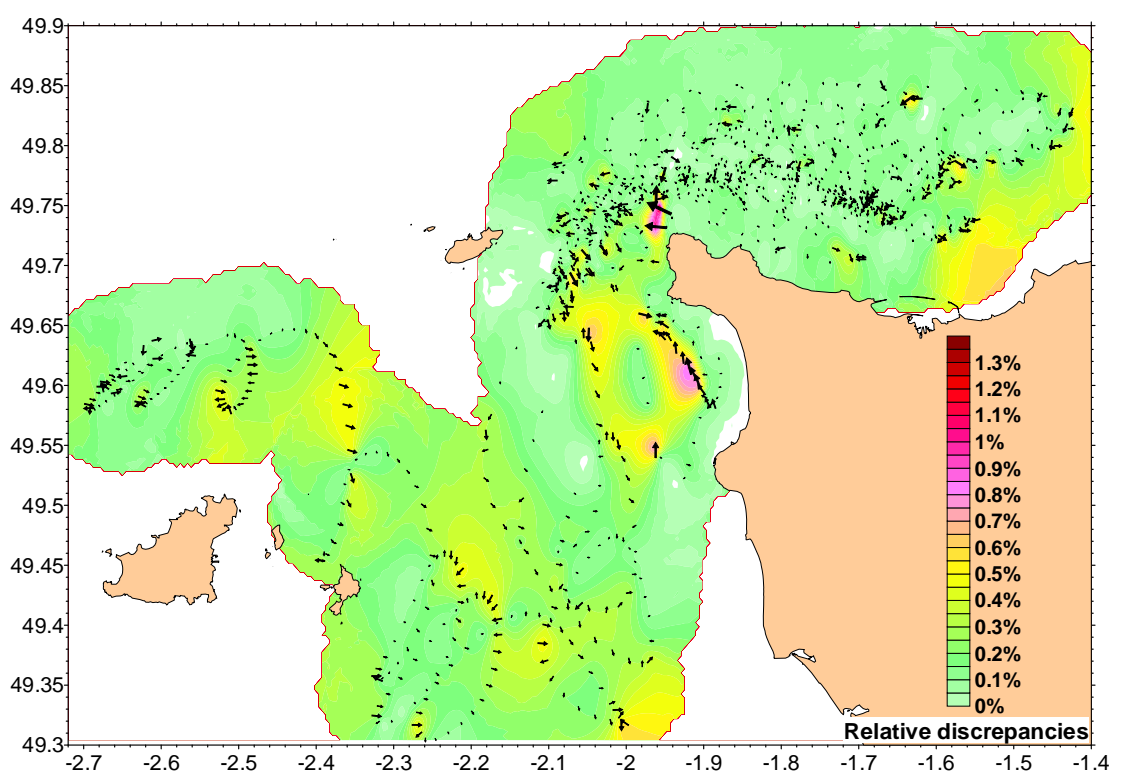

Fig. 10 Comparisons between drifter-measured and simulated instantaneous currents

Overall, this Lagrangian qualification method shows that the qualitative behaviour of the model is satisfactory for short-term transport. Major discrepancies are noted in the medium term (a few days) due to the accumulation of errors inherent in this approach and to the fact that hydrodynamic field gradients are very steep in this area: this has already been observed with water depths, and, apparently, the same also applies to currents. In relation to this, the precision limits found for tidal cycle timing $(15 \mathrm{~min}$.) have an even greater impact as the spatial variations become slower.

Lastly, these discrepancies could also be due to the different nature of observations and modelling: surface currents are involved in the former case, vertically-averaged currents in the latter.

Bearing in mind the intended use of the model (i.e. the simulation of soluble release dispersion), its performance is of interest since we are focusing on durations of less than 48 hours after release initiation. Moreover, the dispersion plume is studied beyond one hour after release, at a point where the plume is vertically homogenized. Consequently, in the following comparisons, we find there is a reduced impact due to the bias between surface and vertically-averaged quantities. 


\section{Characteristics of dispersion}

It is possible to produce general results that are representative of dilution in the study area. Dilution coefficients are calculated over time from the start of the release (Fig. 11). Fig. 12 summarizes the measured plume widths.

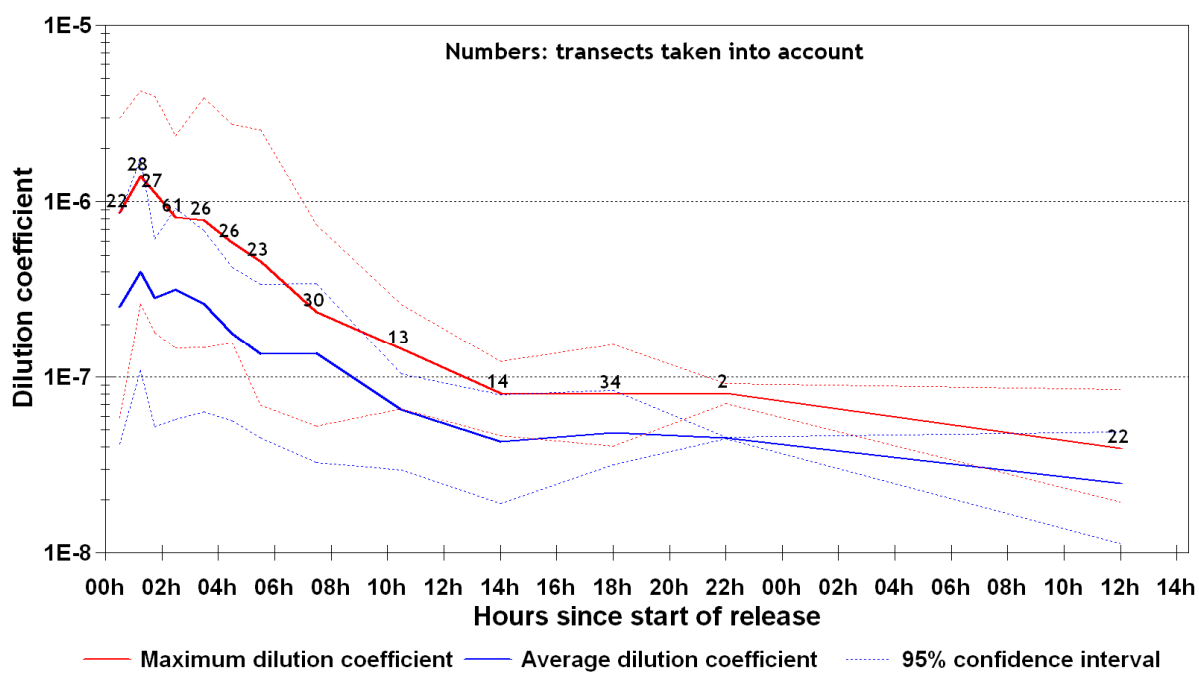

Fig. 11 Dilution coefficients as a function of time since start of release

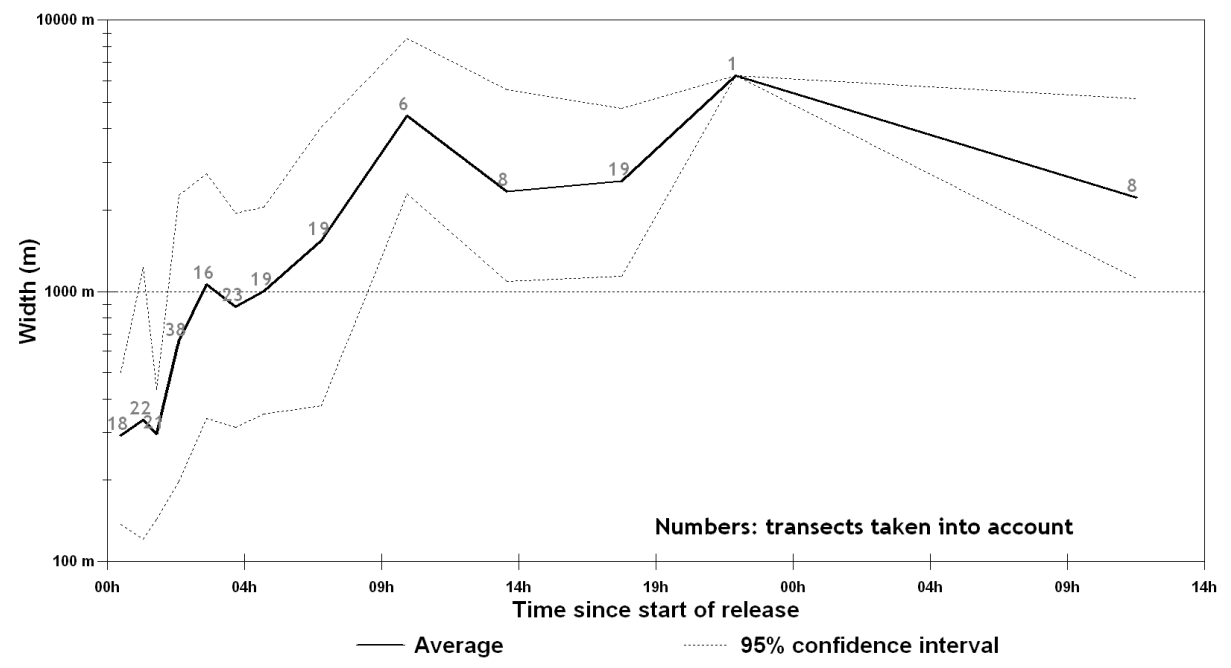

Fig. 12 Plume width as a function of time since start of release

The plume first appears at the surface between 10 and 45 minutes after the start of release, at distances of $800 \mathrm{~m}$ to the south and $1200 \mathrm{~m}$ to the north of the outfall. The more rapid appearance of the plume towards the south is a result of the decreasing water depths south of the release point (outcrops of a rocky plateau called "Les Huquets", Fig. 1). The presence of a rocky plateau prevents collection of seawater samples between 1 and $3 \mathrm{~km}$ south of the outfall, so validation data are lacking in this area (Fig. 4).

Schematically, we can distinguish three main periods:

- Between 1 and 8 hours after the start of release, maximum dilution coefficients vary between $6.10^{-6}$ and $8.10^{-7}$ and mean dilution coefficients between $3 \cdot 6 \cdot 10^{-7}$ and $7.10^{-8}$.

- Between 8 and 24 hours after the start of release, maximum dilution coefficients vary between $8.10^{-7}$ and $2.10^{-7}$, and mean dilution coefficients between $7.10^{-8}$ and $5.10^{-8}$.

- Between 24 and $48 \mathrm{~h}$ after the start of release, the maximum dilution coefficient is $1.10^{-7}$, and the mean dilution coefficient is $4.10^{-8}$. The plume becomes difficult to distinguish from the effects of releases carried out over the previous weeks or months.

\section{Comparison between modelled and measured dispersion}

The originality of this comparison between our model and physical measurements arises from the spatial density of the sampling points used and the high frequency of tritium concentration sampling. These two parameters allow an accurate representation of the dispersion plume released by the La Hague plant within 1 to 48 hours of release initiation. Beyond 48 hours, it becomes impossible to distinguish two consecutive releases from one another due to dilution and mixing between them. In this time frame, about two hundred usable transects were available (i.e. transects crossing a dispersion plume that could be traced back to a known release, and in cases where the width of 
the plume could be determined). These transects represent roughly 3,000 individual measurements which encompass all tide conditions (from neap to spring tides).

Two ranking criteria are used to evaluate the performance of the model: the time from release onset and the distance from the outlet point. Model/ measurement quantification is based on the following criteria:

- $\quad$ Distance between positions of maximal concentrations in plumes;

- $\quad$ Plume width discrepancy;

- $\quad$ Average and maximum concentration discrepancies;

- Dilution rate discrepancy.

The first parameter yields more information on the model's capacity to simulate transport, whereas the three following parameters characterize different aspects of dispersion.

\subsection{Position of the plume}

On average, the discrepancies are less than $100 \mathrm{~m}$ for the time-span ranging from 1 to 48 hours after release. When plotted against the distance travelled (i.e. ranging from 1 to $20 \mathrm{~km}$ ), this discrepancy represents, on average, less than $6 \%$ of the distance from the release point (Fig. 13).

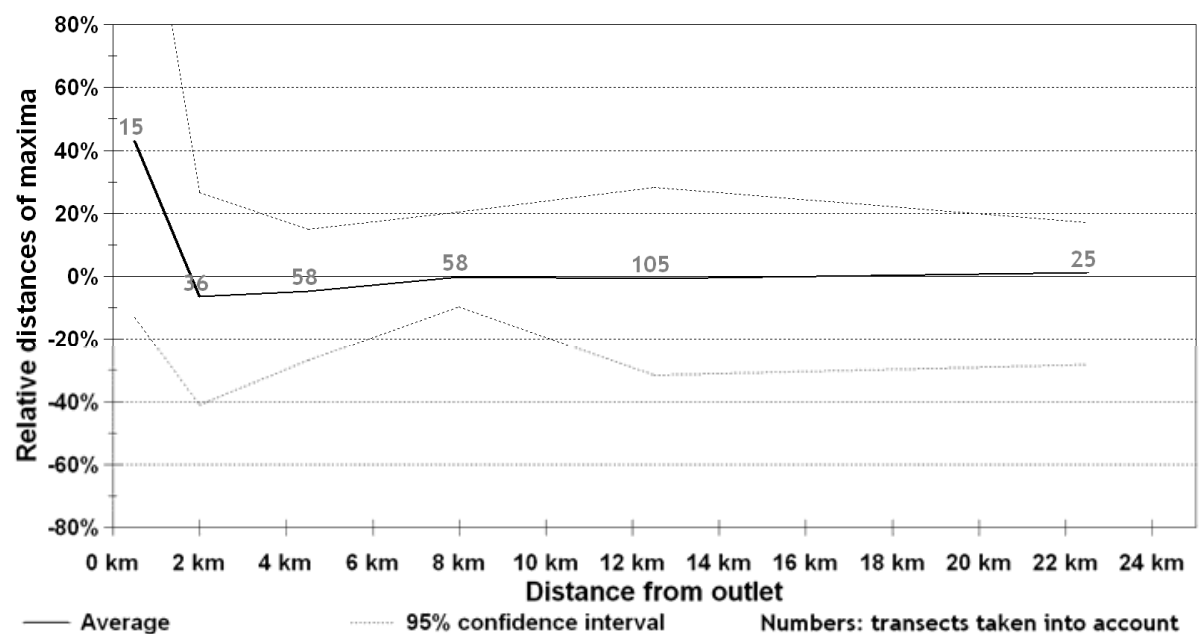

Fig. 13 Relative distances between measured and simulated maxima per transect according to distance from release point

Although some major discrepancies arise in the position of the plume maxima, due to the complex structure of the plumes, the overall dispersion is adequately simulated. A corresponding map is presented in Fig. 14, showing that the plume forms a loop and that the overall position of this loop is fairly consistent with the measurements, although the maxima are $6.6 \mathrm{~km}$ apart (release $\mathrm{n}^{\circ} 3$ around $12 \mathrm{~h} 45$ ).

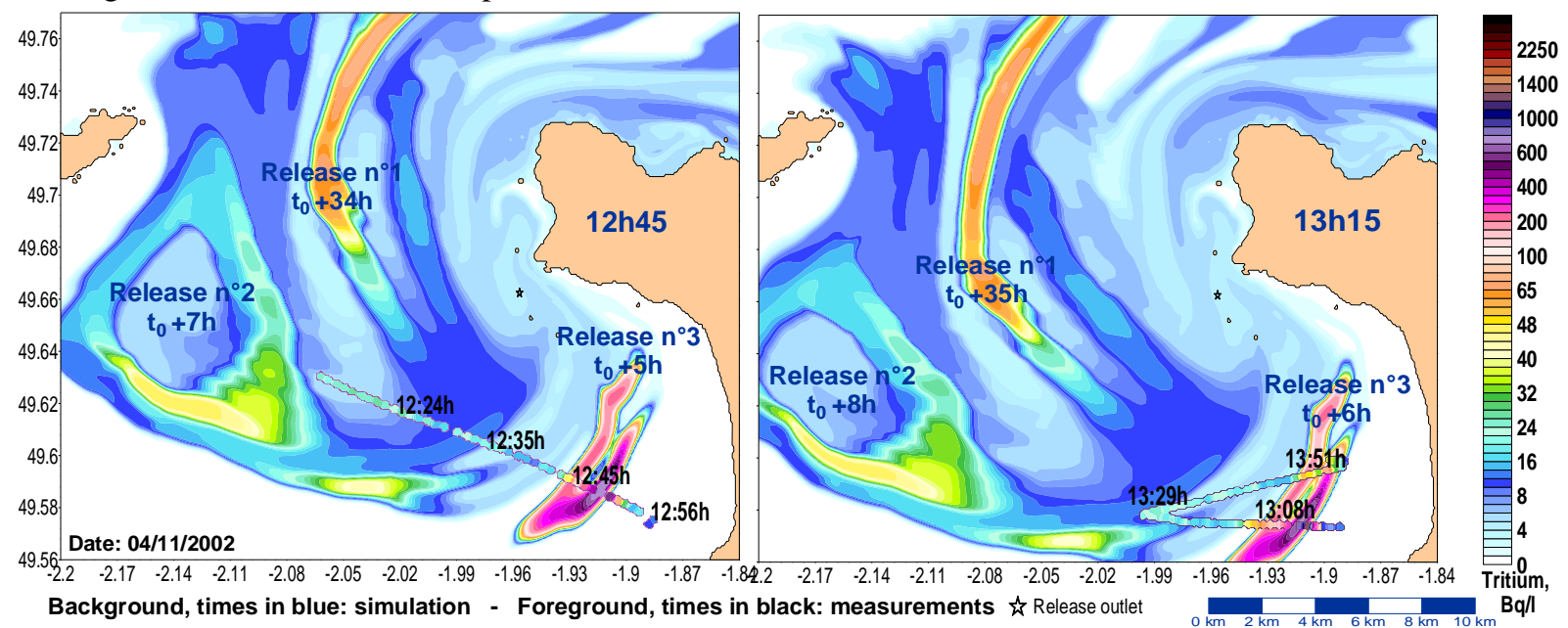

Fig. 14 Complex structure of three consecutive plumes

\subsection{Width of the plume (diffusion)}

To achieve a correspondence between simulated and measured dispersion structures, the diffusion coefficient was calibrated and used in all simulations using the criterion of plume width. The value adopted here is $\mathrm{k}_{\mathrm{t}}=2 \mathrm{~m}^{2} . \mathrm{s}^{-1}$. 
Within two hours of a release, the simulated plumes are, on average, $28 \%$ wider than the measured plumes. This discrepancy stems from the initial dilution of the release in the elementary calculation grid, where the cell size $(110 \mathrm{~m})$ is comparable to the width of the measured plumes $(487 \mathrm{~m})$.

After several tidal cycles, it becomes apparent that discrepancies are related to the complex structure of the plume observed in this particular area (Fig. 14); in fact, the method used to calculate the plume width is not suitable for plumes that show several local maxima.

Within 4 to 24 hours, the average discrepancy between measured and simulated plume widths is less than $20 \%$. Hence, the simulation of plume diffusion by the model does appear to be realistic over this time-scale. Beyond that, the small number of transects and the contribution of the background from previous releases prevents us from drawing any definitive conclusions for longer durations.

\subsection{Dilution coefficients derived from concentration maxima along transects}

A dilution coefficient of $5.610^{-6}$ is the maximum measured from the 316 transects within 1 to 48 hours after release. Comparison of the dilution coefficients for measured and simulated maxima in the plume reveals discrepancies of less than $6 \%$ in the mean value of the coefficients for all the plumes within 1 to 48 hours of release initiation (Fig. 15).

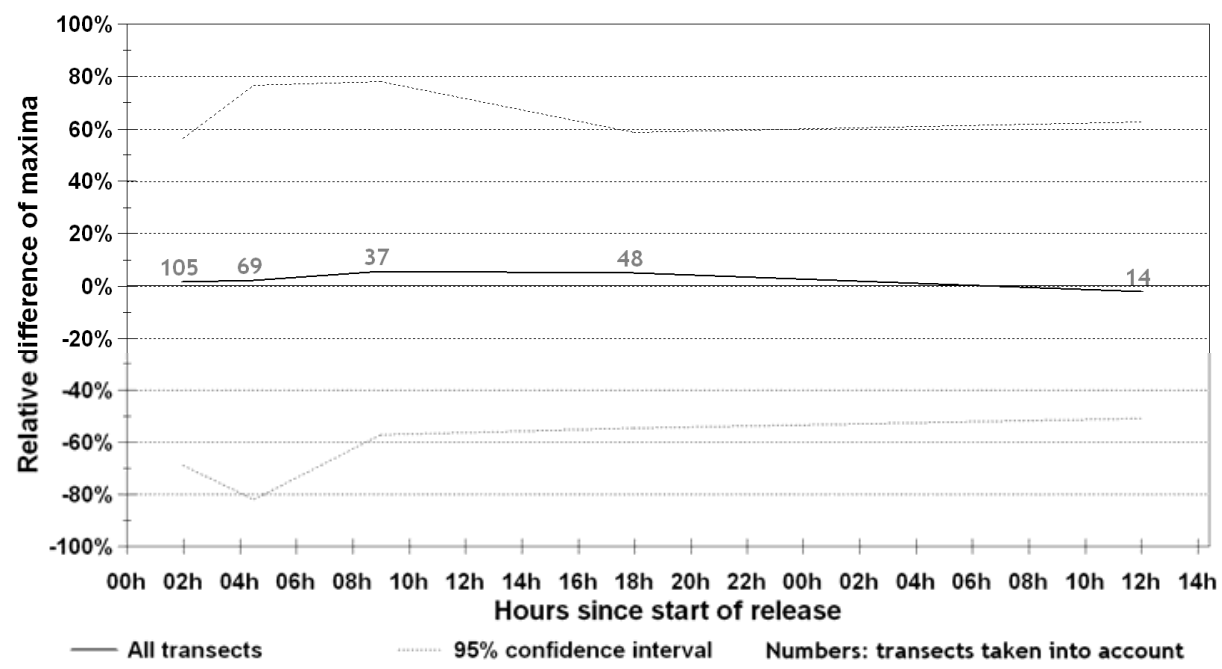

Fig. 15 Discrepancies in dilution coefficients for measured maxima from transects

Analysis of all the data for this time scale reveals an average discrepancy of $3 \%$.

By comparing the dilution coefficients derived from the concentration maxima, we can see a balanced trend, with no significant bias of the model results. The average discrepancy within 1 to 48 hours of release is $3 \%$, associated with a standard deviation of $43 \%$.

The maximum ratio between measured and simulated maximum dilution coefficients never exceeds 20 (and is less than 5 for $95 \%$ of values) for the 176 transects and 3391 individual measurements taken into account within 1 to 48 hours of the releases.

\subsection{Mean dilution coefficients}

On average, discrepancies between simulated and measured dilution coefficients are less than $23 \%$. The mean values of measured dilution coefficients are generally higher than their simulated counterparts, and this discrepancy increases with time. This trend is due to the fact that the model cannot simulate the background resulting from releases occurring more than one week before the studied release. During mean tides, the release plume starts to extend beyond the coverage of the model after 4 days. This limitation induces a systematic underestimation of simulated mean dilution coefficients compared to measured values.

Between 2003 and 2004, the mean value of the tritium activities measured at Goury by the CherbourgOcteville radioecology laboratory was $12 \mathrm{~Bq} / \mathrm{l}$ (Conan et al., 2006). This represents the medium-term background resulting from releases by the nuclear reprocessing plant in this area (Fraizier et al., 1992). In the present study, the average concentration of the releases used to validate the model is $3.10^{+8} \mathrm{~Bq} / \mathrm{l}$. Assuming that dilution coefficients lower than $12 / 3.10^{+8}=4.10^{-8}$ are reached 24 to 48 hours after the release, the recently released plumes would, at the most, double the background. The release plume would thus become difficult to detect.

Thus, beyond 24 hours after the release, the average discrepancy between measured and simulated dilution coefficients is equivalent to a difference of $2.10^{-8}$ in dilution coefficient (Fig. 16), a value easily explained by the influence of the background level. This figure illustrates the capacity of the model to reproduce plume dilution. 


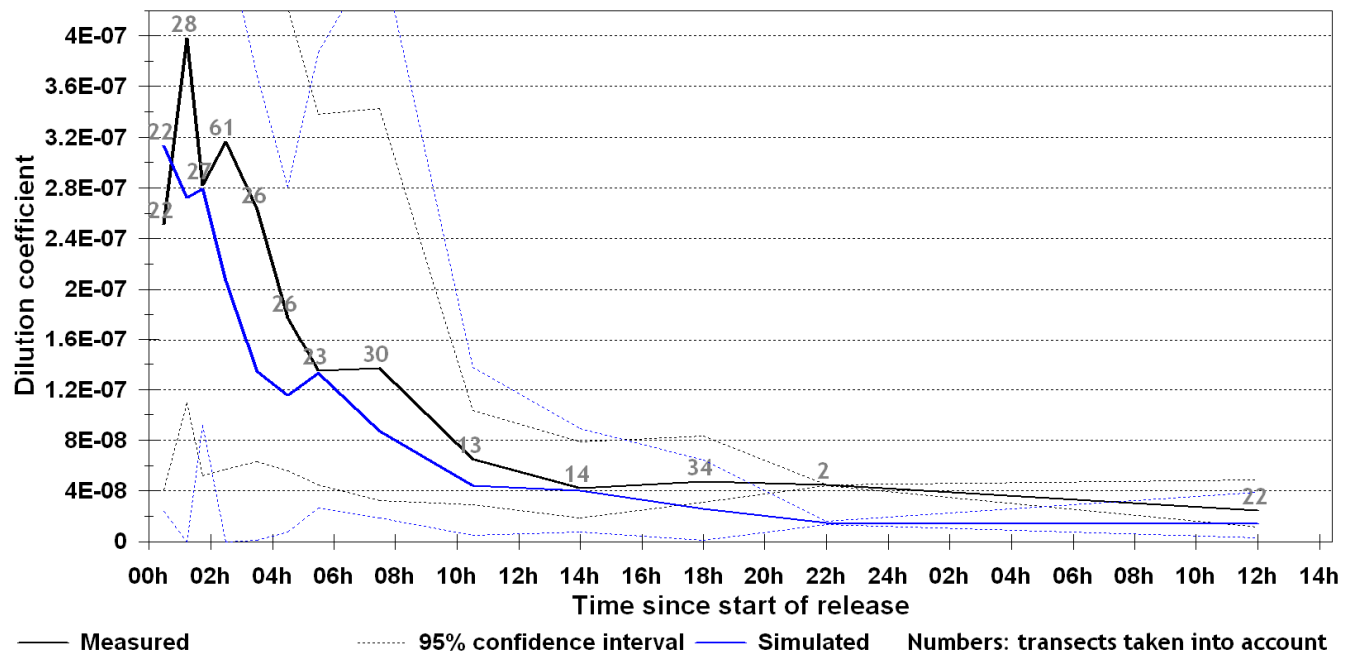

Fig. 16 Measured and simulated mean dilution coefficients measured from transects, 8 to 36 hours after a release

\section{Discussion}

\subsection{Sensitive parameters}

\subsubsection{Applicability of the 2D model}

The results given above demonstrate the reliability of the model from 1 to $48 \mathrm{hrs}$ after start of release. Indeed, because the model is two-dimensional, it simulates concentrations within the whole water column, right from the start of the release. However, since the release outlet is situated on the sea-bed, releases first appear at the bottom and are gradually mixed vertically as they are advected. Therefore, the point of emergence of the simulated plume cannot be compared with the results of measurements that are carried out solely on surface samples. When the release can be measured in the surface water, concentrations can be compared with calculated levels if we account for two sources of bias:

- When a plume appears at the surface, measured concentrations are underestimated compared to the average concentration for the whole water column. This is due to the fact that, as releases are discharged from the bottom of the water column, the plume still lacks vertical homogeneity.

- To introduce the release into the model, the flow has to be homogenized in a computation cell, right from the onset of the release. The cell size of this grid $(110 \mathrm{~m} \times 110 \mathrm{~m})$ leads to an overestimation of the width of the plume during the first few minutes following the release giving underestimated concentrations.

At some distance from the outlet point, both phenomena will compensate for each other, but produce significant discrepancies during the first hour after release at less than $1 \mathrm{~km}$ from the outlet point. A more widely spaced grid model would result in larger discrepancies, since the second source of bias increases proportionally with the cell size of the calculation grid.

The first traces of the plume were measured downstream 20 minutes after release $800 \mathrm{~m}$ southward and 45 minutes after release $1200 \mathrm{~m}$ northward. The more rapid emergence of the plume in the South is probably due to the shallower depths south of the outlet point (rocky reef known as Les Huquets, Fig. 1).

However, from 0 to 1 hour after release initiation, the measured dilution coefficients are of a similar order of magnitude as the simulated values, with an average discrepancy of 30\% for the mean dilution coefficients and $32 \%$ for the maximum dilution coefficients, given that the model overestimates concentrations.

At more than $1 \mathrm{~km}$ from the outlet point, and more than one hour after release, simulated and measured values are always close. These two criteria determine the lower boundary of the range of application of this model.

Between 1 and 48 hours after release, the average discrepancy in the position of plume maxima is $66 \mathrm{~m}$; i.e. of a similar order of magnitude as the computation grid of the model $(110 \mathrm{~m})$ and the spacing of sampling points (160 $\mathrm{m}$, on average).

The average discrepancy in plume widths is $7 \%$, corresponding to an overestimation of simulated widths.

\subsubsection{Temporal calibration}

Given the dynamics and variability of currents in the study area, the temporal accuracy of simulated currents and times of release from the AREVA-NC outfall are determining factors for effective comparisons of models vs. measurements. Some of the uncertainties are associated with the method used for calculating release times, depending on the transit time in the release outfall pipe (several hours). The average inaccuracy on release times is estimated at 15 minutes. This error is not significant for model-measurement comparisons during the first hours after release when the plume is still linear. Measurements are generally carried out in the middle of the longitudinal 
release plume, which persists for one to three hours. This temporal inaccuracy can have a significant effect on model-measurement comparisons when the turn of the tide has altered the linear structure of the plume.

An error in timing of the tidal cycle will have the same consequences. Tidal cycle timing can be verified accurately by calculating the reverse time of the tide at the points where current measurements are carried out (see Fig. 8).

\subsubsection{Bathymetry}

The bathymetry incorporated into the models is another sensitive data. It is crucial to know the bathymetry of area around the outfall, where initial dispersion of the release takes place, which explains why a specific measurement campaign was conducted (see Section 3.1).

\subsubsection{Applicability of model vs. measurement comparisons release by release}

For the AREVA-NC release outfall, Fraizier et al. (1992) and Boust et al. (1995) have shown that radionuclide concentrations measured at the coast result, on average, from the dilution of releases accumulating over 2 to 4 weeks prior to measurement. The dilution factor associated with these measurements was established by studies carried out by the Groupe Radioécologie Nord-Cotentin (GRNC - Nord-Cotentin radio-ecology group, 1999). An average annual dilution coefficient was established by tracking measurements of tritium in seawater, corresponding to $0.76 \mathrm{~Bq} / \mathrm{m}^{3}$ per $\mathrm{TBq}$ released annually. Given the quantities of tritium released from the plant in 2002-2005, this dilution coefficient implies an average concentration of $9.7 \mathrm{~Bq} / \mathrm{l}$ at Goury during this period. The mean concentration currently measured at Goury is $11.6 \mathrm{~Bq} / \mathrm{l}$, which is close to the theoretical value. For model validation, we assume a mean release concentration of $3.10^{+8} \mathrm{~Bq} / \mathrm{l}$ and dilution coefficients lower than $11.6 / 3.10^{+8}$ $\approx 4.10^{-8}$ attained between 24 and 48 hours after release. 48 hours appears to be the maximum period over which we can usefully make a comparison - release by release - between the dilution coefficients measured in the environment and the simulated data. Beyond that time, we need to compare the simulated concentration for each measurement point, taking into account all of the releases leading to that concentration.

\subsubsection{Currents}

Current measurements, obtained from vertical current profiles or drifter tracking, make it possible to refine the reliability of the models with four key parameters: tidal cycle timing measured by the reverse time of the tide (Fig. 8); instantaneous velocity; total of velocities over a tidal cycle (progressive vector diagram Fig. 9); spatial distribution of differences in velocities measured from drifter tracking.

Some of the vertical profiles were obtained at points where depths and currents are homogeneous and representative of the main fluxes in the area (nos. 5, 6, 9, 10, Fig. 1). They can be used to test models with mediumrange resolution $(500 \mathrm{~m}$ to $2 \mathrm{~km})$. Other profiles require models with higher horizontal and vertical resolution and greater bathymetry accuracy to yield a correct representation of the complexity of local currents.

The measurements show very pronounced current gradients towards certain small bays (St Martin, Ecalgrain; Fig. 1). Transient secondary eddies are observed in these areas that follow directions contrary to the main currents. Plume dispersion in online resource 2 reveals the different eddies resulting from currents variations (online resource 3 ). Even some resonance effects can be detected (periodic variations in current direction and velocity with a period of around ten minutes).

\subsection{Diffusion coefficients}

A lateral diffusion coefficient can be calculated from measurements made on release plume transects in the hours following the dispersion of identified releases.

Numerous studies have reported diffusion coefficients. In 1997, Elliott and al discusses diffusion in Irish coastal waters ; in 2000, Riddle and Lewis produced a compilation for English coastal waters, and their values can be compared with those obtained here. Longitudinal diffusion is not discussed here because releases are not instantaneous. Riddle determined the lateral diffusion coefficient with the following formula:

$$
\sigma_{y}^{2}=\sigma_{y 0}^{2}+2 K_{y} t
$$

Assuming a normal distribution, the plume width measured at half height $\mathrm{W}$ (section 4.6, Fig. 5) allows calculation of $\sigma$ with $W=2.3548 \sigma . \mathrm{K}$ is calculated taking the start of release as a reference, with $\sigma_{y 0}^{2}=0$ and $\mathrm{t}=\mathrm{t}_{\text {transect }}-\mathrm{t}_{\text {release. }}$. A total of 117 transects could be used in this way, yielding a mean $\mathrm{Ky} \mathrm{of} 9.3 \mathrm{~m}^{2} / \mathrm{s}$ with minimum and maximum values of $0.29 \mathrm{~m}^{2} / \mathrm{s}$ and $76 \mathrm{~m}^{2} / \mathrm{s}$, respectively. The highest values of Ky observed after two hours from the start of release (Fig. 17) can be attributed to spreading of the plume caused by eddies observed at the reverse of the tide. 


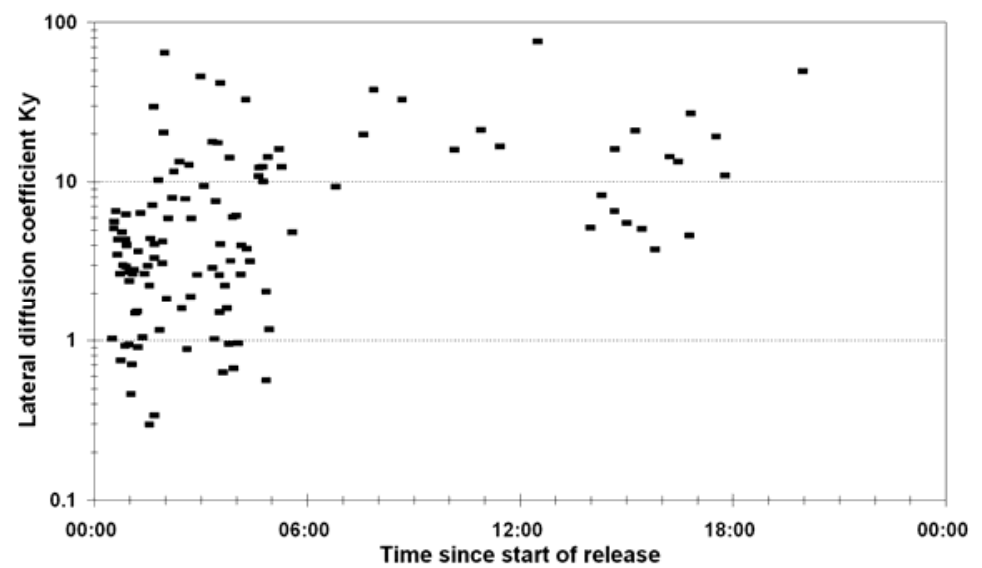

Fig. 17 Lateral diffusion coefficient measured as a function of time from the start of release

Theses large scale eddies of about 300-3000 meters width are responsible of higher values of Ky (76). Fig. 18 illustrates this situation. It does not corresponds to usual definition of Ky resulting of diffusion from short scale eddies. It is a particularity of this area to generate large scale eddies which exhaust dilution of the plume.

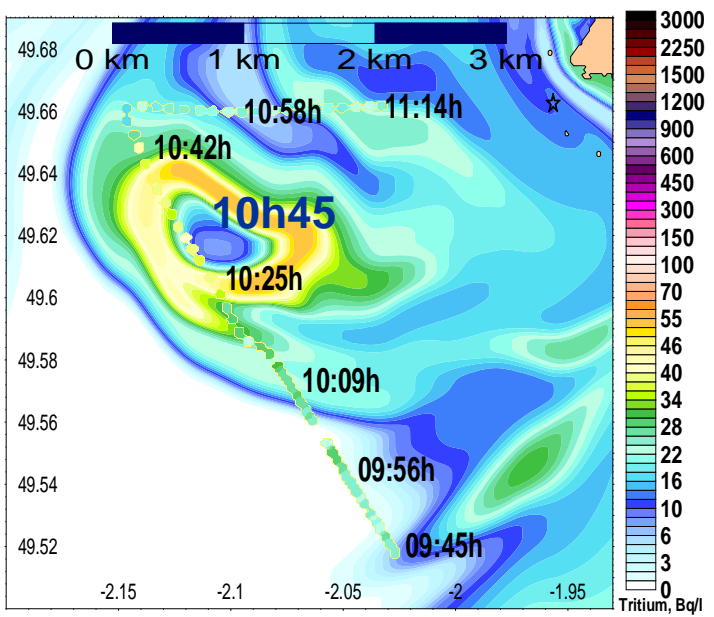

Background colours: simulated concentrations, foreground spots: measured concentrations; blue hours: simulation time; black hours: measurement time

Fig. 18 Example of large scale eddy which result of unrealistic diffusion coefficient Ky.

We exclude the values of Ky when the plume is not longitudinal in order to fit with classical plume measurements. A total of 105 transects could be used in this way, yielding a mean $\mathrm{Ky} \mathrm{of} 5.9 \mathrm{~m}^{2} / \mathrm{s}$ with minimum and maximum values of $0.29 \mathrm{~m}^{2} / \mathrm{s}$ and $21 \mathrm{~m}^{2} / \mathrm{s}$, respectively.

Compared with the Riddle and Lewis data compilation (2000) and Elliott and al. (1997), the present values are higher than those measured around the British Isles and Ireland, the highest being obtained at Cowes (West Solent) with minimum, median and maximum values of $1.94 \mathrm{~m}^{2} / \mathrm{s}, 3.82 \mathrm{~m}^{2} / \mathrm{s}$ and $10.6 \mathrm{~m}^{2} / \mathrm{s}$, respectively. Wind has no strong influence on diffusion.

The elevated diffusion values around Cap de la Hague result from a combination of particularly strong currents and shallow water depths next to the coasts which generate strong turbulent flow due to lateral current shear.

\subsection{Applicability of tracer data}

As a supplement to already published studies, the data collected here make it possible to investigate dispersion phenomena in a macro-tidal sea from a time scale of one hour to several years.

To represent the dispersion of soluble releases from the La Hague plant, we can distinguish scales representative of the principal phenomena in relation to the time after release. In the following list, we give the time scales of dispersion and main references concerning the La Hague outfall:

1. Between one minute and one hour $(10 \mathrm{~m}$ to $10 \mathrm{~km})$ : vertical dispersion of the plume, small-scale turbulence (work in progress).

2. Between $1 \mathrm{~h}$ and 2 days (1-50 km): influence of alternating tidal currents (Ausset and Farges 1968; Lapicque 1974).

3. Between 2 days and 3 months $(5-200 \mathrm{~km})$ : merging of individual plumes, transition between the predominant effect of the tide or the wind on dispersion (Fraizier et al. 1992; Boust et al. 1995; Orbi and Salomon 1988).

4. Between 3 months and 10 years $(30-1000 \mathrm{~km})$ : effect of individual tides is no longer detectable, dispersion depends on the combined influence of the residual tidal current, meteorological forcing and possibly general 
circulation patterns (Bailly du Bois et al. 1995, 1997, 1999; Bailly du Bois and Dumas 2005; Salomon and Breton 1993; Salomon et al. 1993, 1995; Breton and Salomon 1995;).

The time scaling ratio from one domain to another is around 50 while the space dimension ratio is around 5. The different scales are especially well marked in the case of releases from the La Hague plant; they could be representative for other macro-tidal seas.

\section{Conclusion}

Mathematical hydrodynamic models are now sufficiently reliable to be used for the simulation of realistic dispersion at all scales. Validation by field data is the best way to assess the reliability of models. In the marine environment, representation of tracer dispersion is of particular interest since it incorporates all of the processes and constraints involved: bathymetry, currents, diffusion, tidal and meteorological forcing. The Cap de la Hague area and data collected since 1988 offers an exceptional opportunity for this validation, as the dynamics of the water masses in this region are particularly intense and complex. The region is characterized by extremely strong currents, complex topography and pronounced gradients in tidal range, making it particularly sensitive for the simulation of dispersion of soluble substances. In addition to previously published data, a total of 14493 soluble radio-tracer measurements presented here make it possible to track the dispersion of releases from the AREVA-NC plant in a consistent manner from the hour following release up to several years. Owing to the abundant associated physical measurements, probably no other area is the object of such precise knowledge on extensive temporal and spatial scales in terms of hydrodynamics and dispersion. Hence, the data collected in-situ provide a 'benchmark' for the testing and comparison of different models.

Measurements of radiotracers, physical parameters, bathymetry and drifter tracking were collected, edited and processed with the aim of facilitating their use in the validation of dispersion models. We propose methods for comparing models with physical measurement to test models against several criteria.

Results corroborate the particular features of the studied area from the point of view of currents and dispersion:

- Tide records indicate a mean tidal range gradient of $2 \mathrm{~m}$ between two points $5 \mathrm{~km}$ apart.

- Most dilution occurs within the 24 hours following the release. Over longer time spans, concentrations added by more recent releases are of the same order of magnitude as the background level resulting from previous releases. During the first 24 hours, it is possible to track the fate of individual releases. Beyond this scope, comparisons between measured and simulated concentrations must account for the influence of several releases. To simulate these phenomena, models must be able to represent dispersion simultaneously on different temporal and spatial scales (i.e. a few minutes, $100 \mathrm{~m}$; months, $100 \mathrm{~km}$ ).

- Diffusion coefficients are particularly high in the studied area, showing higher values than those measured around the Ireland and British Isles. It results from shear turbulence associated to particularly strong currents close to the coasts.

Comparison with the model presented leads us to draw the following conclusions:

- No systematic discrepancy can be found between simulated and measured concentrations, since both values are always similar.

- The major part of plume dilution occurs within the 24 hours following the release; after 48 hours, concentrations are of a similar order of magnitude as those resulting from releases occurring in the preceding weeks.

- $\quad$ The measured and simulated plumes are always located in the same area.

Table 5 sums up the main characteristics of the model regarding the simulation of dispersion of dissolved substances in seawater. 


\begin{tabular}{|c|c|}
\hline \multicolumn{2}{|l|}{ Physical characteristics } \\
\hline Geographical boundaries of the model & $249^{\circ} 17^{\prime} \mathrm{N}-49^{\circ} 55^{\prime} \mathrm{N} ; 2^{\circ} 26^{\prime} \mathrm{W}-1^{\circ} 31^{\prime} \mathrm{W}$ \\
\hline Dimensions & $\begin{array}{l}\text { Two-dimensional: Vertically-averaged velocities and } \\
\text { concentrations, } 110 \mathrm{~m} \text { mesh size, } 20 \mathrm{~s} \text { time step }\end{array}$ \\
\hline Mechanisms simulated & $\begin{array}{l}\text { Advection and dispersion of dissolved substances in } \\
\text { seawater }\end{array}$ \\
\hline Spatial applicability of the model & 1 to $20 \mathrm{~km}$ from the outlet point \\
\hline Operational time frame of the model & 1 to 48 hours after release initiation \\
\hline Precision in time & 15 min (time step lower than 20 seconds) \\
\hline Discrepancies between measured and simulated instantaneous velocities & less than $5 \%$ average discrepancy \\
\hline Discrepancies between measured and simulated Eulerian residual velocities & (5 to $30 \%$ discrepancies in distance \\
\hline \multicolumn{2}{|c|}{ Dispersion characteristics $1 \mathrm{~h}$ to $\mathbf{4 8}$ hours after release } \\
\hline $\begin{array}{l}\text { Average discrepancy between the mean dilution coefficients measured and } \\
\text { simulated in the plumes }\end{array}$ & $9 \%(-66 \%->70 \%)$ \\
\hline Maximal values of dilution coefficients measured in surface waters & $\begin{array}{c}5.610^{-6} \\
1.5 \text { to } 4 \text { hours after release, less than } 6 \mathrm{~km} \text { from the outlet } \\
\text { point }\end{array}$ \\
\hline $\begin{array}{l}\text { Average discrepancy per transect between simulated and measured maximum } \\
\text { dilution coefficients }\end{array}$ & $3 \%(-72 \%->73 \%)$ \\
\hline Average measured/simulated plume-width discrepancy & $-6 \%(-73 \%->65 \%)$ \\
\hline $\begin{array}{c}\begin{array}{c}\text { Average discrepancy between measured and simulated plume-position, as a function } \\
\text { of distance from the outlet point }\end{array}\end{array}$ & $-1 \%(-22 \%->22 \%)$ \\
\hline
\end{tabular}

Figures in brackets indicate the 95\%-confidence interval.

Table 5 Characteristics of the model used to simulate soluble radioactive release dispersion in seawaters around the Cap de La Hague

Given the features discussed above, we can point out the following limitations of this model for the simulation of release dispersion:

- Because of its geographical boundaries, the model is unable to simulate release dispersion over more than a few days when the plume reaches the limits of the model.

- Discrepancies are detected concerning the spatial extension of plumes (North of the Cap de La Hague and around the plateau of Les Huquets) as well as the temporal phasing of the model (15-minute discrepancy between measured and simulated flood- and ebb-tide durations). These discrepancies are mainly due to an imperfect representation of tidal currents. Different ways of improving this are: updating bathymetric data; using much more precise solutions than Schwiderski (1983) to represent the tides over the entire continental shelf (Le Roy and Simon 2003). These solutions should take better account of non-linear tidal waves (quarter-diurnal and sixth-diurnal components), which are difficult to model accurately. Improve the Strickler's coefficient used in the model. Herry et al. (2007) have presented a method that takes into account this precise forcing mechanism without degrading windrelated circulation (crucial on time scales longer than 48 hours). Spatial variation of this coefficient accounting for bottom roughness could also be investigated.

- The main shortcoming in covering the different scales of dispersion concerns the near-field domain within $1 \mathrm{~km}$ from the outfall and from 0 to 1 hour after a release. At this scale three-dimensional phenomena predominate and tracer samples must be taken at all depths for a full 3D model validation. Such work is in course and the database will be supplemented as it progresses.

Despite these limitations, after tuning and validation our model does provide a satisfactory representation of tracer dispersion and hydrodynamics in the area of the Cap de La Hague, under both real and theoretical conditions. It is able to provide information on local hydrodynamics, including the overall circulation of water masses and small-scale eddies near the outlet point (cove of St Martin, bay of Ecalgrain). We show the model to be representative of a study area that is exceptionally dynamic and complex, so it should be usable with reasonable confidence in other megatidal areas of the English Channel or elsewhere. Such a tool could be extremely useful for analysing and interpreting dissolved substances or radionuclide measurements acquired in the past, for operational mode forecasting (planning of sampling campaigns, fates of accidental releases in the area), for research purposes or as a decisional aid (impact on the environment due to changes in release conditions).

All data collected in this work are accessible in DISPRO database (Datasets \#762253). The validation tool proposed wish to be an open and evolving resource. 


\section{Acknowledgements}

This research work would not have been possible without the willingness and efficiency of the crew of the INSU-CNRS oceanographic vessel N/O Côtes de la Manche. It also relied on the unstinting support of the radiological protection department (SPR) of the AREVA-NC plant, which provided us with financial support and release data at all hours of the day and night. Lionel Tenailleau, of the Groupe d'Etudes Atomiques de la Marine Nationale, the IRSN laboratories at LMRE and STEME provided essential support in carrying out the tritium measurements. We are also particularly grateful to Claire Voiseux, Didier Hébert, Bruno Fiévet, Marianne Rozet, Olivier Connan, Philippe Riou, Frédéric Goldshmidt and Gildas Gouret for taking hundreds of samples at time steps of 30 seconds under difficult conditions. M.S.N. Carpenter post-edited the English style.

We dedicated this work to Jean Claude Salomon, who initiates model validation by radiotracers measurements, and was a great stimulation in scientific discussions and model improvement.

\section{References}

Ausset, R., Farges, L., 1968. Utilisation de la rhodamine B dans l'étude des caractéristiques hydrologiques d'un site marin de rejets d'effluents radioactifs. Rev Intern Oceanogr Med IX 167-188.

Baeza, A., Garcia, E., Miro, C., Perianez, R., 2006. Modelling the spatio-temporal evolution of $3 \mathrm{H}$ in the waters of the River Tagus. Journal of Environmental Radioactivity Volume 86, Issues 3, Pages 367-383.

Bailly du Bois, P., Guéguéniat, P., Gandon, R., Léon, R., Baron, Y., 1993. Percentage contribution of inputs from the Atlantic, Irish Sea, English Channel and Baltic into the North Sea during 1988 : a tracer-based evaluation using artificial radionuclides. Netherlands Journal of Sea Research 31(1), 1-17.

Bailly du Bois, P., Salomon, J.C., Gandon, R., Guéguéniat, P., 1995. A quantitative estimate of English Channel water fluxes into the North Sea from 1987 to 1992 based on radiotracer distribution. Journal of Marine Systems 6 (5-6), 457-481.

Bailly du Bois, P., Rozet, M., Thoral, K., Salomon, J.C. 1997. Improving knowledge of water-mass circulation in the English Channel using radioactive tracers. Radioprotection - colloques, April 1997, Numéro spécial "Radionuclides in the Oceans", RADOC 96-97, Proceedings Part 1 "Inventories, behaviour and processes" Cherbourg-Octeville (France), 7-11 October, 1996 Edited by : P. Germain, J.C. Guary, P. Guéguéniat and H. Métivier 32 (C2), 63-69.

Bailly du Bois, P., Guéguéniat, P., 1999. Quantitative assessment of dissolved radiotracers in the English Channel: sources, average impact of la Hague reprocessing plant and conservative behaviour (1983, 1986, 1988 and 1994). Continental Shelf Research ; FluxManche II dedicated volume 19, 1977-2002.

Bailly du Bois, P., Germain, P., Rozet, M., Solier, L., 2002. Water masses circulation and residence time in the Celtic Sea and English Channel approaches, characterisation based on radionuclides labelling from industrial releases. Proceedings from the International Conference on Radioactivity in Environment, Ed. by Peer Borretzen, Torun Jolle, Per Strand Monaco 1 - 5 September 2002, 395 - 399

Bailly du Bois, P., Dumas, F., 2005. Fast hydrodynamic model for of medium- and long-term dispersion in seawater in the English Channel and southern North Sea, qualitative and quantitative validation by radionuclide tracers. Ocean Modelling 9, 169-210.

Bailly du Bois, P., 2010. Automatic calculation of bathymetry for coastal hydrodynamic models. Computers and Geosciences, ss press. doi:10.1016/j.cageo.2010.11.018

Boust, D., Hairie, A., Fraizier, A., Baron, Y., 1995. Analyse et prédiction de la dispersion des radioéléments dans l'environnement marin par la méthode de la réponse impulsionnelle. Oceanologica Acta 18(6):617-629.

Connan, O., Rozet, M., Solier, L., Voiseux, C., 2006. Mesures des radionucléides dans l'eau de mer par le Laboratoire de Radioécologie de Cherbourg-Octeville (LRC) sur le site de Goury (Nord Cotentin) pour études radioécologiques. Note technique IRSN/DEI/SECRE 2006-016.

Breton, M., Salomon, J.C., 1995. A 2D long-term advection-dispersion model for the Channel and southern North Sea. Part A: validation through comparison with artificial radionuclides. Journal of Marine Systems 6(5-6):495514.

Elliott, A.J., Barr, A.G., Kennan, D., 1997. Diffusion in Irish coastal waters. Estuarine, Coastal and Shelf Science 44A, 15-23.

Fraizier, A., Guéguéniat, P., Salomon, J.C., 1992. Aspects temporels de l'impact de rejets radioactifs, effectués en mer, sur les eaux d'une station littorale de la Manche. Oceanologica Acta 15(1):75-85.

Groupe Radioécologie Nord Cotentin (GRNC), Ledenvic, P., Calmet, D., Amiard, J.C., Bailly du Bois, P., Boilley, D., Bordier, J.C., Bretheau, F., Dellero, N., Desbordes, R., Dubois, G., Le Corre, A., Leclerc-Cessac, E., Lissorgues, G., Marchand, O., Merle-Szeremeta, A., Rommens, C., Siclet, F., 1999. Rapport du sous-groupe $\mathrm{n}^{\circ} 3$ : Modèles de transfert des radionucléides dans l'environnement. IPSN - Clamart 500p.

Guéguéniat, P., Bailly du Bois, P., Gandon, R., Salomon, J.C., Baron, Y., Léon, R., 1994. Spatial and Temporal distribution (1987-91) of ${ }^{125} \mathrm{Sb}$ used to trace pathways and transit times of waters entering the North Sea from the English Channel. Estuarine, Coastal and Shelf Science 39, 59-74

Guéguéniat, P., Bailly du Bois, P., Gandon, R., 1995a. Estimation of La Hague contribution to the artificial radioactivity of Norwegian waters (1992-1996) and Barents sea (1992-1997). In : Environmental radioactivity in the Arctic Ed P Strand, A Cooke, Osteras 102-107 
Guéguéniat, P., Bailly du Bois, P., Salomon, J.C., Masson, M., Cabioch, L., 1995b. Fluxmanche radiotracers measurements: A contribution to the dynamics of the English Channel and North Sea. Journal of Marine Systems 6, 483-494.

Guéguéniat, P., Herrmann, J., Kershaw, P., Bailly du Bois, P., Baron, Y., 1997a. Artificial radioactivity in the English Channel and the North Sea. Radionuclides in the Oceans, inputs and inventories", RADOC 96-97, Les Editions de Physique, Coordinators : P. Guéguéniat, P. Germain, and H. Métivier 121-154.

Guéguéniat, P., Kershaw, P., Herrmann, J., Bailly du Bois, P., 1997b. New estimation of La Hague contribution to the artificial radioactivity of Norwegian waters (1992-1995) and Barents Sea (1992-1997). The Science of the Total Environment 202, 249-266.

Herrmann, J., Kershaw, P.J., Bailly du Bois, P., Guéguéniat, P., 1995. The distribution of artificial radionuclides in the English Channel, southern North Sea, Skagerrak and Kattegat, 1990-1993. Journal of Marine Systems 6 (5-6) 427-456.

IRSN, 2003. Résultats de l'intercomparaison 71 SH 300 - Mesure de l'activité de 2 radionucléides, émetteurs b purs, dans un échantillon d'eau souterraine. IRSN juillet 2003 8p.

Kautsky, H., 1988. Artificial radioactivity in the North Sea and the northern north Atlantic during the years 1977 to 1986. IAEA, Hambourg 1988. IAEA-TECDOC-481 71-102.

Kershaw, P.J., McCubbin, D., Leonard, K.S., 1999. Continuing contamination of north Atlantic and Arctic waters by Sellafield radionuclides. The Science of The Total Environment 237-238 (30), 119-132.

Lapicque, G., 1974. Etude de l'environnement marin d'une usine atomique et du comportement des traceurs rejetés (circulation, diffusion, fixation, sédimentation). Rapport CEA CEA-N-1745, 141p.

Lazure, P., Dumas, F., 2008. An external-internal mode coupling for a 3D hydrodynamical model for applications at regional scale (MARS). Advances in Water Resources 31 (2), 233-250.

Niiler, P.P., Sybrandy, A.S., Bi, K., Poulain, P.M., Bitterman, D., 1995. Measurements of the water following capability of holey sock and TRISTAR drifters. Deep Sea Research, Part I 42, 1951-1964.

Orbi, A., Salomon JC. 1988. Dynamique de marée dans le Golfe Normand-Breton. Océanologica Acta 11 (1), 55 64.

Povinec, P.P., Bailly du Bois, P., Kershaw, P.J., Nies, H., Scotto, P., 2003. Temporal and spatial trends in the distribution of 137Cs in surface waters of Northern European Seas--a record of 40 years of investigations. Deep Sea Research Part II: Topical Studies in Oceanography 50 (17-21) 2785-2801.

Pujol, L., Sanchez-Cabeza, J.A., 2000. Use of tritium to predict soluble pollutants transport in Ebro River waters (Spain). Environmental Pollution 108 (2) 257-269.

Riddle, AM., Lewis, R.E., 2000. Dispersion Experiments in UK Coastal Waters. Estuarine, Coastal and Shelf Science 51 (2), 243-254.

Salomon, J.C., Guéguéniat, P., Orbi, A., Baron, Y., 1988. A lagrangian model for long term tidally induced transport and mixing Verification by artificial radionuclide concentrations. In : Radionucléides : A tool for oceanography Cherbourg 1-5 juin 1987, Ed Guary, JC, Guéguéniat, P, Pentreath, RJ, Elsevier Applied Science Publishers 384394.

Salomon, J.C., Guéguéniat, P., Breton, M., 1991. Mathematical model of $125 \mathrm{Sb}$ transport and dispersion in the Channel. In : Radionuclides in the study of marine processes Norwich, UK, 10-13 september 1991, Ed Kershaw JP, Woodhead DS Elsevier Applied Science 74-83.

Salomon, J.C., Breton, M., 1993. An atlas of long-term currents in the Channel Oceanologica Acta 16 (5-6), 439448.

Salomon, J.C., Breton, M., Guéguéniat, P., 1993. Computed residual flow through the Dover Strait. Oceanologica Acta 16, 5-6, 449-455.

Salomon, J.C., Breton, M., Guéguéniat, P., 1995. A 2D long term advection-dispersion model for the Channel and southern North Sea. Part B: Transit and transfer function from Cap de La Hague Journal of Marine Systems Vol $6 \mathrm{~N}^{\circ}$ 5-6 515-528.

Schwiderski, E.W., 1983. Atlas of ocean tidal charts and maps, part 1: the semidiurnal principal lunar tide M2. Marine Geodesy 6, 219-265.

DISPRO database: http://www.ifremer.fr/sismerData/jsp/campagnesALaMer.jsp projet: DISPRO, select: “a campaign" / "Ensemble des données du projet DISPRO" or upload directly from: http://www.ifremer.fr/sismer/catal//campagne/docscan/DISPRO.zip accessed 10 November 2010.

Online resource 1: Tide propagation over the English Channel (InSituDatabaseToolbox_1.mpg)

Online resource 2: Plume dispersion around the La Hague Cape, 17/05/2003 - 16/06/2008, real release, meteorological and weather conditions (InSituDatabaseToolbox_2.mpg).

Online resource 3: Current vectors around the La Hague Cape during 72 hours (InSituDatabaseToolbox_3.mpg).

Dataset \#762253 Supplementary data are available at http://doi.pangaea.de/10.1594/PANGAEA.762253 (DISPRO database).

Details :

Dataset \#762186 DISPRO bathymetry: http://doi.pangaea.de/10.1594/PANGAEA.762186 
Dataset \#762193 and \#762198, DISPRO drifters http://doi.pangaea.de/10.1594/PANGAEA.762193, http://doi.pangaea.de/10.1594/PANGAEA.762198

Dataset \#762261 DISPRO tritium http://doi.pangaea.de/10.1594/PANGAEA.762261,

Dataset \#762255, \#762256, \#762257, DISPRO tide gauge http://doi.pangaea.de/10.1594/PANGAEA.762257, http://doi.pangaea.de/10.1594/PANGAEA.762255, http://doi.pangaea.de/10.1594/PANGAEA.762256,

Dataset \#762262-762381 DISPRO current measurement: http://doi.pangaea.de/10.1594/PANGAEA.762262, 762369, 762371, 762373, 762374, 762375, 762376, 762377, 762378, 762380, 762381

Dataset \#762186 Tritium releases: http://doi.pangaea.de/10.1594/PANGAEA.762428. 